\title{
M eeting the challenges related to material issues in chemical industries
}

\author{
BALDEV RAJ, U KAMACHI MUDALI, T JAYAKUMAR, \\ $K V$ KASIVISWANATHAN and R NATARAJAN
}

M aterials, Chemical and Reprocessing Groups, Indira Gandhi Centre for A tomic Research, Kalpakkam 603 102, India

e-mail: dmg@ igcar.ernet.in

MS received $30 \mathrm{M}$ arch 2000

Abstract. Reliable performance and profitability are two important requirements for any chemical industry. In order to achieve high level of reliability and excellent performance, several issues related to design, materials selection, fabrication, quality assurance, transport, storage, inputs from condition monitoring, failure analysis etc. have to be adequately addressed and implemented. Technology related to nondestructive testing and monitoring of the plant is also essential for precise identification of defect sites and to take appropriate remedial decision regarding repair, replacement or modification of process conditions. The interdisciplinary holistic approach enhances the life of critical engineering components in chemical plants. Further, understanding the failure modes of the components through the analysis of failed components throws light on the choice of appropriate preventive measures to be taken well in advance, to have a control over the overall health of the plant. The failure analysis also leads to better design modification and condition monitoring methodologies, for the next generation components and plants. At the Indira Gandhi Centre for A tomic Research (IGCAR), Kalpakkam, a unique combination of the expertise in design, materials selection, fabrication, NDT development, condition monitoring, life prediction and failure analysis exists to obtain desired results for achieving high levels of reliability and performance assessment of critical engineering components in chemical industries. Case studies related to design, materials selection and fabrication aspects of critical components in nuclear fuel reprocessing plants, NDT development and condition monitoring of various components of nuclear power plants, and important failure investigations on critical engineering components in chemical and allied industries are discussed in this paper. Future directions are identified and planned approaches are briefly described.

Keywords. Reliability; materials development; nondestructive testing; condition monitoring; failure analysis. 


\section{Introduction}

A s we enter the new millennium, several chemical industries set up in the past few decades will be subjected to design and technological changes, and associated economic constraints. A ddition of larger, more automated, highly sophisticated and complex components will become necessary. Issues of life estimation and extension of existing plants have to be addressed to overcome the loss in production and to conserve raw materials. A s new plants are constructed and existing plants modernised and automated, every possible effort is needed to cut costs and increase efficiency, and in this way increase profits. M aintenance of components becomes increasingly expensive and complex due to several advances that have taken place by way of modernisation or for increasing profitability, and for avoidance of unexpected failure of critical components. As a consequence, maintenance is increasingly critical, downtime of the plant is less tolerable and reliability and safety of the equipment/components become increasingly important. $M$ aterials, techniques and methodologies that offer greater benefits in the way of higher output, efficiency, improved availability, increased safety and lower maintenance are being constantly incorporated in strategic life-cycle management of several chemical plants. M onitoring the condition of the operating chemical plant is of increasing importance with growing awareness of the need to obtain the best possible financial return by demanding the highest levels of reliability of the components. Reliability is the ability of a component to perform a required function under stated conditions for a stated period of time. It is difficult to separate reliability and maintenance, as there are no components which are perfectly healthy under plant-operating conditions. Every component in the plant undergoes some kind of corrosion, wear, fracture, cracking, surface degradation, loss in conductivity, magnetism etc. during service. Hence, prior knowledge of the reliability of each component/equipment is of paramount importance in scientific maintenance planning. B oth reliability and profitability can be achieved by careful attention to a few most important factors, namely, materials selection and design, fabrication and quality control, operation and maintenance, condition monitoring, failure analysis, life prediction and life extension. Judicious and current technology-weighted attention to these factors leads to achieving greater reliability and profitability of chemical plants (figure 1).

2. Design, materials selection, fabrication and quality control of critical components

Design, materials selection, fabrication, quality control etc. are the important parameters that determine the reliability of components in the chemical plant (M cNaughton 1980). It is important and necessary to give adequate weightage and consideration right from the beginning for selecting materials for a component, followed by several other factors like cost, availability, properties, feasibility for replacement and repair, flexible design, easy fabrication and commissioning, maintenance etc. Each material has its characteristic physical and chemical-interaction properties, some of which change with the prevailing environment. For example, most materials have reduced strength and corrosion resistance at increased temperatures. Material properties can be changed by thermomechanical treatment, by microstructure changes during fabrication, by combining with other materials (alloying, making into a composite, or lining/cladding/coating/surface modification), by providing anodic/cathodic protection, and/or by use of inhibitors and passivators. In any given environment, the selected material system will have a specific corrosion rate that 


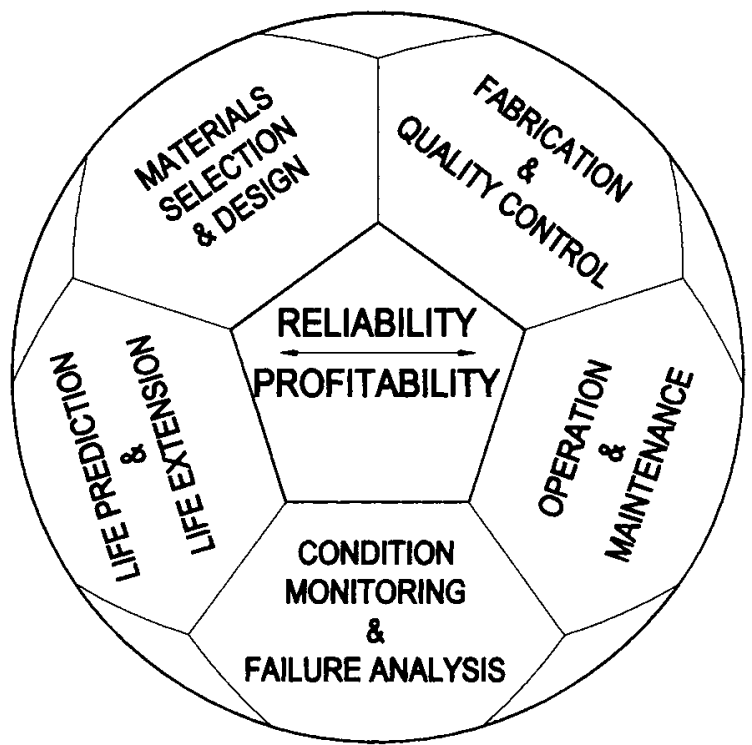

Figure 1. Factors affecting reliability and profitability of chemical industries.

determines the service life of a product or equipment made from it. The strength of the selected material in the prevailing environmental conditions, and the given design and operational life largely determines the thickness of the sections necessary for the expected loading or pressures. This in turn determines the quantity of material and fabrication sophistication. Often, the choice of material and design limits the choice of fabrication methods for forming it to the shape and dimensions of a component or equipment. The quantity of material needed, which includes waste or scrap from fabrication, the unit cost of the material, the fabrication cost, and the cost of any corrosion control measures determine the capital cost of the component. Different combinations of material systems and designs have different capital costs and lifespans.

\section{Development of materials for nuclear fuel reprocessing plants}

The Department of A tomic Energy is establishing fast reactor technology for meeting growing power demands in the future and for effective utilisation of thorium-based fuels for future power plants (R odriguez \& Lee 1996; Chidambaram 1997). In Kal pakkam, fast reactor technology has been demonstrated with synchronisation of power from the experimental fast breeder test reactor (FBTR) to the grid during 1997. Design of the prototype fast breeder reactor (PFBR) of $500 \mathrm{MWe}$ capacity has been completed, and construction is to be started in 2001 to produce power by the year 2008. It is envisaged that the growth of fast breeder reactor programme by 2020 will produce a power output of $2500 \mathrm{M}$ We with $4 \times 500 \mathrm{M} \mathrm{W}$ e additional power plants by 2018. O peration of fast breeder reactors (FBRs) needs significant quantities of high plutonium-containing fuel. This is possible by reprocessing the spent fuel of pressurised heavy water reactors (PHWRs) and FBRs. Indeed, India has opted for the closed fuel cycle, realising the growing demands of power and the inevitable role nuclear energy is destined to play in meeting the national aspirations of energy security and the associated better quality of life. The construction of 
reprocessing plants in the country would need about 6000 tonnes of sheets and 2000 tonnes of pipes of select grades of AISI (A merican Iron and Steel Institute) type 304L SS alloy. In addition, there would be a need of about 100 tonnes of Ti-5\% Ta or zircaloy-2 for the fabrication of electrolytic dissolvers and evaporators. Reprocessing plants are required to match the power production of $20000 \mathrm{M}$ We by 2020 (DA E Vision 2020). A nticipating such a demand for materials and associated processes, emphasis has been focussed on the materials and fabrication technology development for reprocessing plants.

\subsection{Electrolytic dissolver - a critical component for fast reactor nuclear fuel reprocessing plants}

The fast breeder test reactor at $\mathrm{K}$ alpakkam is unique and different from other operating nuclear reactors in the country with respect to the high plutonium $(70 \%)$ containing $(\mathrm{U}, \mathrm{Pu}) \mathrm{C}$ fuel. In order to achieve high dissolution of the spent fuel from FBTR and to overcome the difficulties due to the formation of interfering organics, an electrolytic dissolution method has been developed at IGCAR, Kalpakkam (Palamalai et al 1991). The electrolytic dissolution is carried out with boiling conc. nitric acid $(>10 \mathrm{~N})$ by the passage of current through corrosion-resistant electrodes. The final dissolved solution contains several fission products and other redox ions. The corrosion resistance of the material chosen for the fabrication of the dissolver vessel is of paramount importance as the failure of the component leads to leakage of radioactive plutonium-containing liquid to the plant area, which is not acceptable. M aterials selection for various unit operations (Kamachi

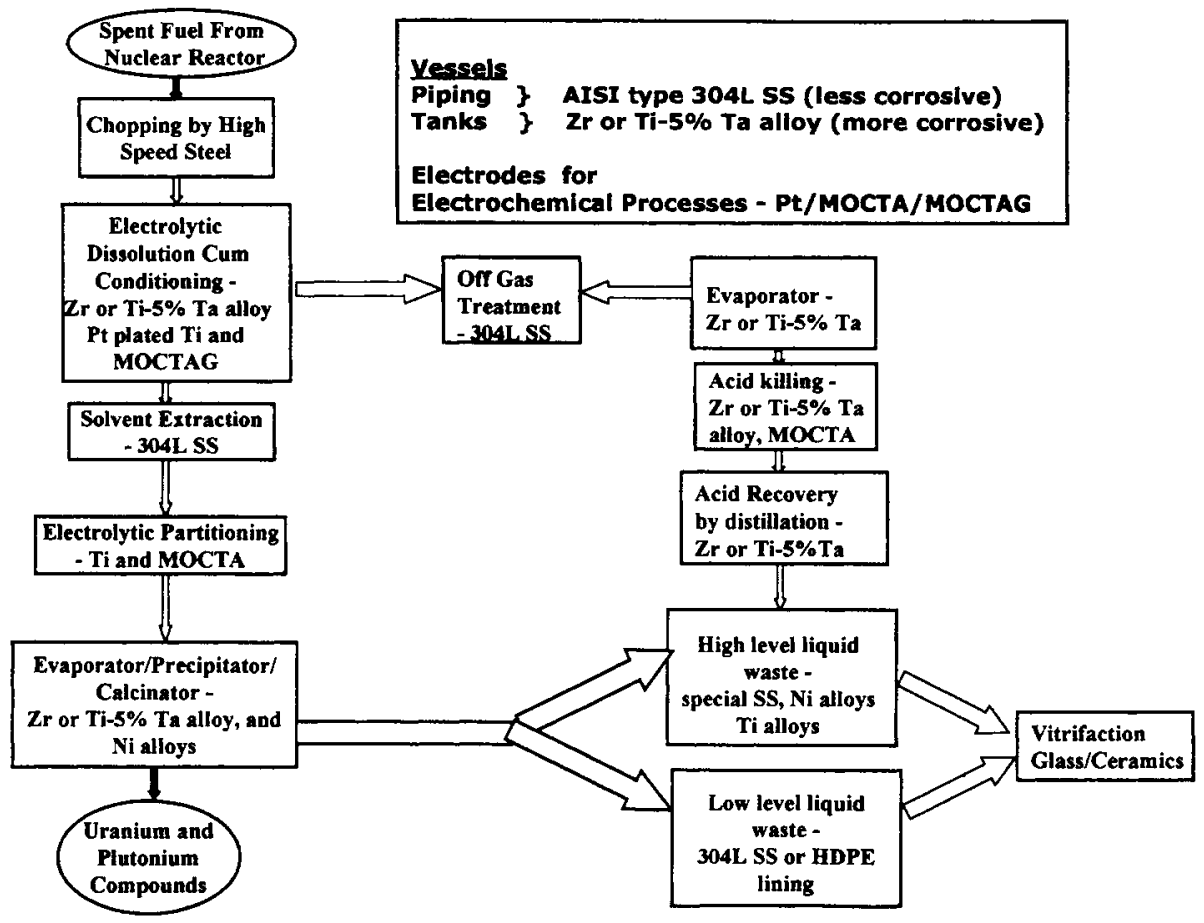

Figure 2. Materials requirement for various unit processes in nuclear fuel reprocessing plants. 
Mudali et al 1986; Gnanamoorthy \& Balasubramanian 1987) involving highly corrosive and radioactive conditions thus play a major role in avoiding unexpected failures and in uninterrupted operation of the plant (figure 2). In the present paper, an attempt is made to highlight material selection, design, fabrication etc. of the 'el ectrolytic dissolver' which is used for the reprocessing of the spent nuclear fuel of the fast breeder test reactor (FBTR) at Kalpakkam. A unique synergism of expertise in the areas of materials technology, corrosion control, chemical processing, design engineering and quality management has enabled meeting the challenge of developing an electrolytic dissolver successfully. Complete harmony among the specialists with diverse areas of expertise and the tradition of meeting the challenges have produced a few spin-off technologies in addition to completing the development indigenously.

\subsection{M aterials selection}

In fuel reprocessing plants, nitric acid is the main process medium which is used from room temperature to boiling point, in dilute to concentrated solution, and also in the presence of several fission products and redox ions (Kamachi Mudali et al 1990, 1993, 1995). AISI type 304L stainless steel is the chief construction material used in the plant. For example, in a typical nuclear fuel reprocessing plant of $100 \mathrm{~kg}$ heavy metal/day capacity, about 750 tonnes of AISI type 304L SS is used for the fabrication of several vessels, tanks, equipment and piping. In general, nitric acid is used at a concentration of $6 \mathrm{~N}$ for major unit operations. However, for applications involving dissolution of the fuel, concentration of the waste volume by evaporation etc., concentrations beyond $10 \mathrm{~N}$ and temperatures above 358K are used. Under these conditions, the stainless steel components are reported to corrode due to transpassive dissolution of the passive films. While testing AISI type 304L SS with boiling nitric acid for $240 \mathrm{~h}$ as per ASTM A 262 practice C test, severe intergranular corrosion and dropping of grains from the surface has been observed (K amachi Mudali et al 1993) (figures 3a \& b). Selective dissolution occurs at inclusions emerging from the surface and this leads to the occurrence of tunnel corrosion (figure $3 c$ ). Even advanced stainless steels with controlled impurities like S, P etc., and addition of Si, $\mathrm{Cr}$ etc. have been found to exhibit intergranular corrosion (figures $3 \mathrm{~d} \&$ e). Hence it is necessary to choose an advanced material which can withstand the severe corrosive environment with minimum corrosion damage. Figure 4 shows the isocorrosion chart for several materials in nitric acid media of various concentrations and temperatures. It is clear that only a handful of materials can be used for applications involving severe nitric acid conditions. Studies carried out in our laboratory have indicated that materials like $\mathrm{Ti}$ and $\mathrm{Zr}$ are promising ones for such critical applications as they show least corrosion rates below 1 mil per year (mpy) $)^{1}(K$ amachi Mudali et al 1993, 1995) (figure 5). These materials are available in the country in various sizes and shapes, and methods for their fabrication are well within our technological capabilities.

The corrosion evaluation of conventional AISI type 304L SS is presently carried out as per A STM A 262 practice C (HUEY test). This is an accelerated test involving boiling nitric acid of $65 \%$ concentration and the experiments are conducted by immersing the test coupon for five successive 48-hour periods in the solution. The major drawbacks of this test procedure are that the specimens are tested in highly concentrated media, nitric acid is in a

\footnotetext{
${ }^{1}$ mpy unit, one thousandth of an inch per year, is used throughout the paper for the convenience of engineering personnel.
} 


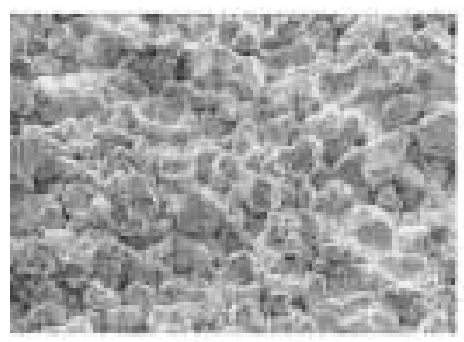

(a)

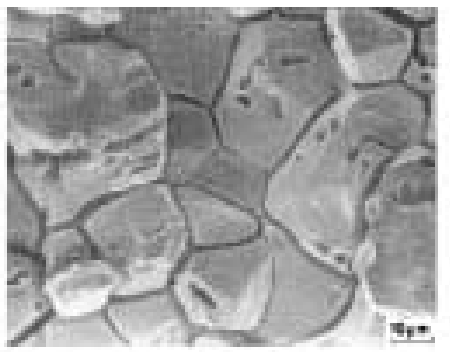

(b)

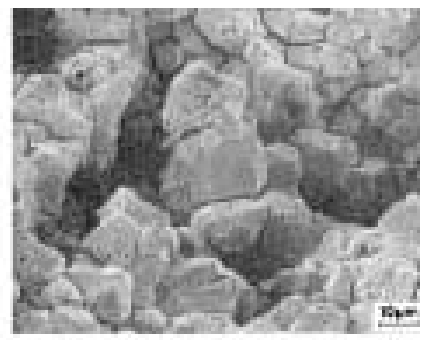

(c)

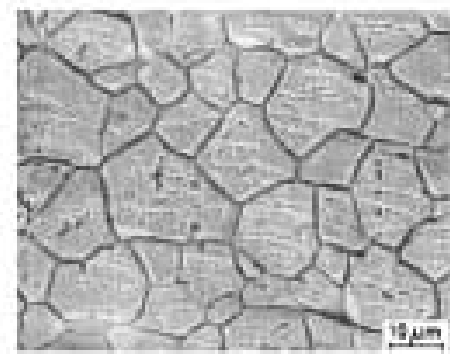

(d)

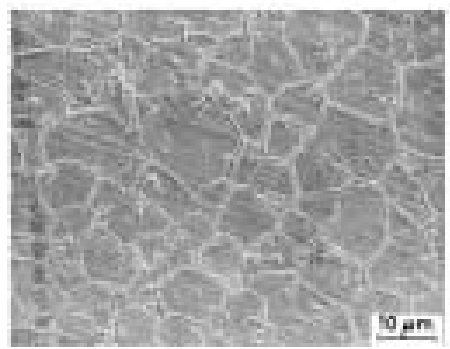

(e)

Figure 3. SEM micrographs showing corrosion attack after corrosion test in boiling nitric acid medium for $240 \mathrm{~h},(\mathrm{a})$ intergranular corrosion, (b) grain dropping during IGC, and (c) tunnel corrosion, all of type 304L SS, (d) IGC attack on URA NUS 16 SS (low carbon, impurity controlled), and (e) IGC attack on URANUS 65 SS to lesser degree (high chromium, low silicon, impurity controlled).

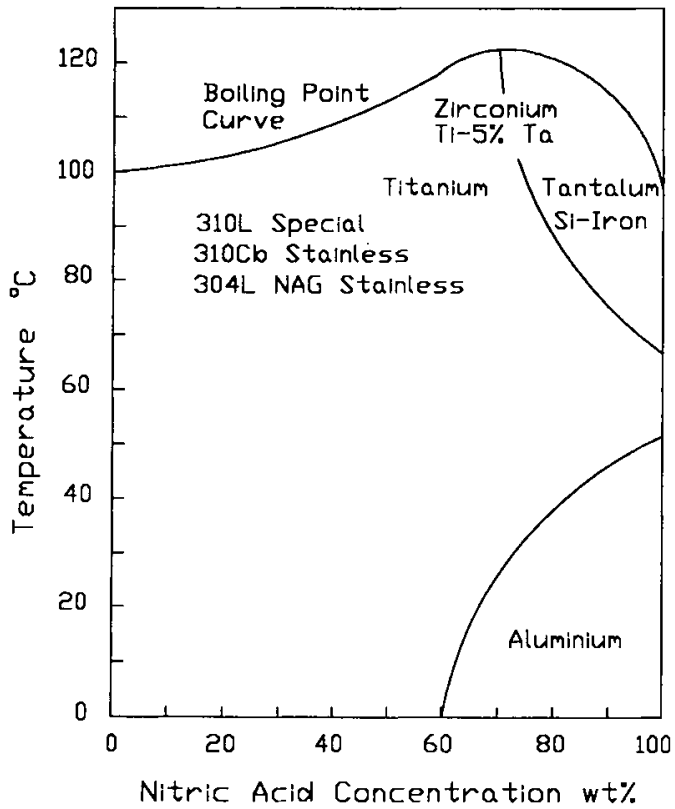

Figure 4. Advanced materials selection for nitric acid service. 


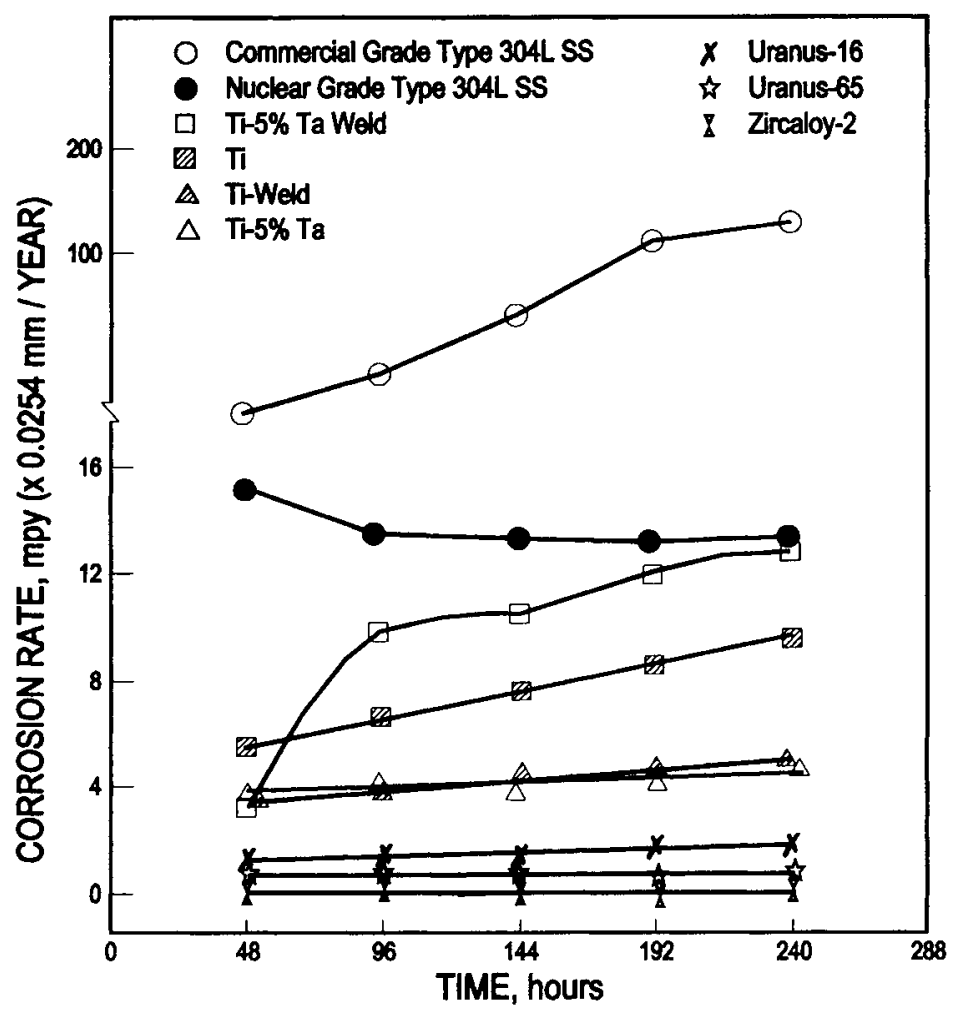

Figure 5. Corrosion rate of various materials in boiling nitric acid medium.

static condition, the total test period is short, and it is specific only for evaluating intergranular corrosion. The testing procedure only guarantees failure or passing of the materials against intergranular corrosion, and does not simulate actual plant conditions. It is well-known that AISI type 304L SS used in nitric acid medium undergoes several types of corrosion, namely, end-grain attack, tunnelling corrosion, transpassive dissolution, vapour phase attack etc., other than intergranular corrosion. So, it is evident that complete corrosion assessment of AISI type 304L SS by A STM A 262 practice C test is impossible, taking into consideration the ranges of concentration of nitric acid used, temperature of operation, impurities and redox chemicals present, and the metallurgical state of the materials used in the reprocessing plants. This necessitates the need for designing a dynamic nitric acid loop, with flowing nitric acid at different temperatures, made of AISI type 304L SS to evaluate the corrosion performance of materials used in reprocessing plants (figure 6). Corrosion resistance of the materials under different metallurgical conditions, namely, cold working, solution annealing and sensitizing heat treatment, alloy composition etc. is evaluated in this loop in flowing nitric acid at different flow velocities (up to $1.55 \mathrm{~m} / \mathrm{s}$ ) and temperatures (313,333, 353, $380 \mathrm{~K}$ and vapour phase). The data generated over long periods of exposure are used to arrive at acceptable corrosion rates of AISI type 304L SS used for applications in nitric acid service. Further, modelling of the corrosion process is done using the data generated which are useful in predicting the remaining life of the existing components used in the inaccessible radioactive as well as inactive areas of the reprocessing plants. 


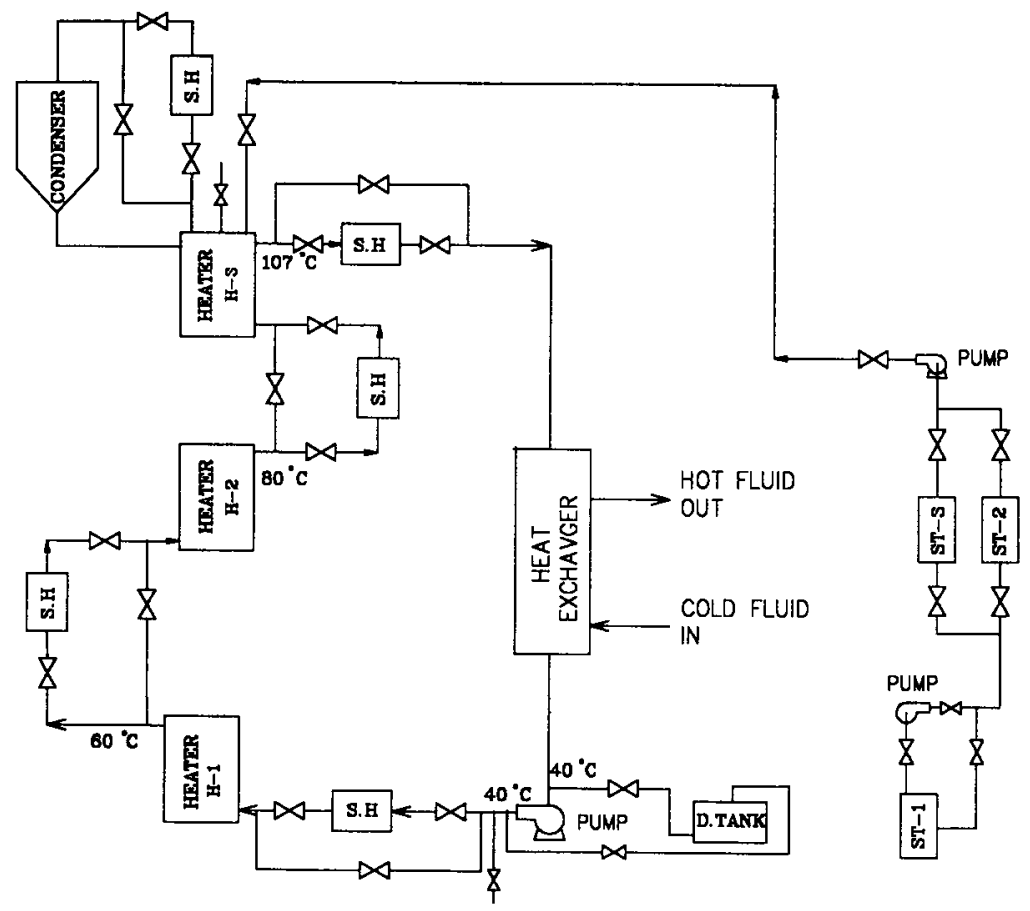

Figure 6. Diagram showing the schematic of dynamic nitric acid loop.

Titanium, despite being a highly reactive metal, exhibits excellent corrosion resistance in a wide range of environments and is an excellent choice for use in sea water, chlorinated water, nitric acid, wet chlorine, hypochlorite, and chloride environments (IMI, Report). Its corrosion resistance is derived from a very stable, self-repairing, and non-porous film formed on the surface in many chemical media. Titanium exhibits excellent corrosion resistance to all concentrations of nitric acid at most temperatures, and has been reported to be a candidate material for use except in the vapour phase and condensate zones (Steele 1986). In the vapour phase and condensate regions, titanium forms a less protective, white and nonadherent hydrated $\mathrm{TiO}_{2}$ layer instead of the typical dark, adherent and crystalline $\mathrm{TiO}_{2}$ layer (Steele 1986). Based on the extensive research and development work carried out on the corrosion aspects of the material in as received and welded condition, and its availability, fabrication expertise and cost, titanium (Grade 2) was chosen as the material for construction of the electrolytic dissolver of the FBTR fuel demonstration reprocessing plant at Kalpakkam. The dissolver vessel and a part of the piping inside the cell which demands high quality standard of inspection during various stages of construction, erection and associated piping, is made of titanium (Grade 2). The raw materials were specified as per ASTM specification for plates, rounds, pipes and filler wires. A coupon of raw material was subjected (Kamachi M udali et al 1998) to three-phase corrosion (liquid, vapour and condensate) test in boiling concentrated (13 M ) nitric acid containing $\mathrm{Cr}^{6+}$ and $\mathrm{Ag}^{2+}$, and corrosion rates were determined (table 1 ). Corrosion rates observed after $500 \mathrm{~h}$ test duration were $1 \mathrm{mpy}, 6 \mathrm{mpy}$ and $1 \mathrm{mpy}$ in liquid, vapour and condensate phase respectively, which is within the acceptable limits. Corrosion rates were not significantly affected after welding as shown in table 1 . Though Ti-5\% Ta alloy exhibited excellent corrosion resistance in 


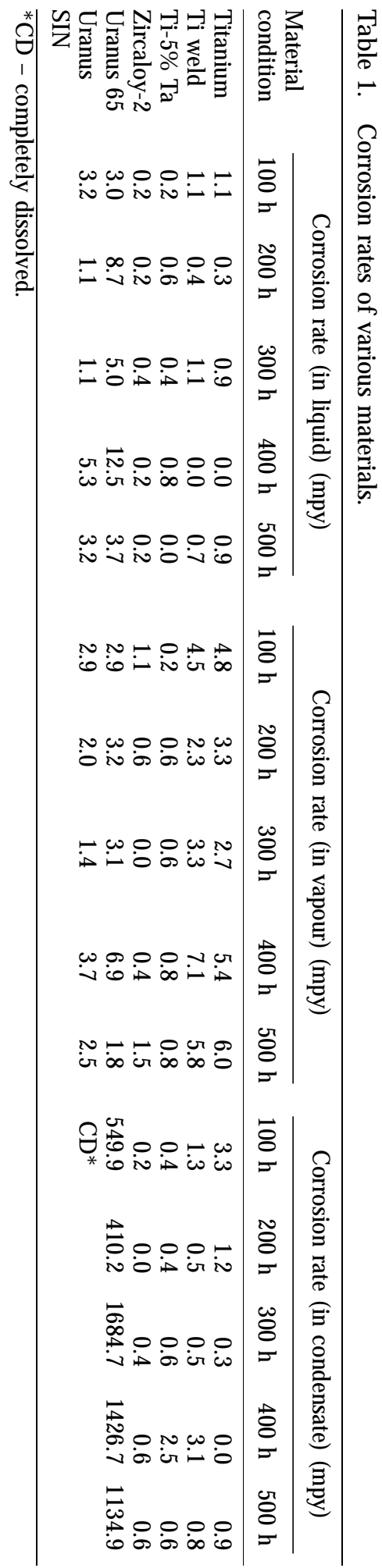

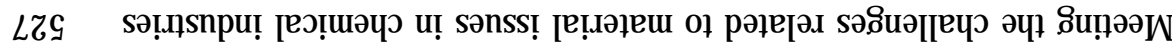


comparison with $\mathrm{Ti}$ Grade 2, it is more expensive and currently has to be imported. Zircaloy-2 also showed excellent corrosion resistance in all conditions. However, the decision was taken to fabricate the electrolytic dissolver using titanium, based on our fabrication experience and its availability in all sizes and shapes. Various quality control measures were evolved for fabricating this high quality component as the failure of the item would lead to an unacceptable situation with loss of fissile material. Introducing a new material like titanium in a reprocessing plant where all components are made of stainless steel alloys posed a great challenge with respect to fabrication and linking the dissolver to the rest of the plant. However, the excellent synergism of expertise available with various groups in IGCAR, enabled us to overcome the difficult situations which arose during various stages of design, material selection, fabrication, inspection, quality control, erection and commissioning.

\subsection{Design, fabrication and spin-off technologies}

The unique design of the vessel for handling the high Pu-content spent fuel was evolved by the Reprocessing Group of IGCAR, Kalpakkam for dissolving $1 \mathrm{~kg}$ of the fuel per batch (A nanda Rao et al 2000). The sketch of the dissolver is shown in figure 7. The dissolver has a facility for changing the electrode assembly, while holding the chopped fuel pin basket apart from the process nozzle provisions. Initially a mock-up piece of the titanium main body was welded to different nozzles for fuel entry, feed, vent, liquid-vapour circulation pump etc. for establishing welding parameters for developing good quality and corrosionresistant joints.

The welding of titanium is carried out by the GTAW process with inert gas purging, shielding and trailing. The filler wire used is titanium (Grade 1 ) conforming to A merican Society for Mechanical Engineers (ASME) SFA 5.16 ER Ti-I and the electrode is $2 \%$ thoriated tungsten. The purity of argon gas is $99.995 \%$ minimum. A part from carrying out the welding procedure qualification (in 6G position of 100 NB Sch 40 pipe), meeting the ASME Section IX requirement, the three-phase corrosion test of welded specimen in $11.5 \mathrm{M}$ boiling nitric acid is specified as mandatory requirement. The critical $\mathrm{V}$-full groove fillet weld joint of nozzle to main vessel as shown in figure 7, posed a challenging task in meeting the requirement of ASME Section III with supplementary requirement of obtaining $100 \%$ defect-free radiographic results in order to achieve high corrosion resistance. Hence a mock-up qualification of this joint was carried out prior to actual dissolver fabrication, and radiography was done by the single-wall double imaging technique. Though specifications allow for a repair of the weld joint once, all the welded joints meeting the specification requirements without any repair were achieved in the fabrication of the electrolytic dissolver. This is attributed to methodical and systematic developmental efforts put in by the interdisciplinary team working in complete harmony.

\subsection{Development of double oxide coating on titanium for reconditioning (DOCTOR)}

During the qualification of the raw materials procured for the electrolytic dissolver, and the welding procedure for welding the vessel, the results indicated that titanium showed abnormal and unacceptable corrosion rates in the A STM A 262 practice C test (HUEY Test) in 11.5 M nitric acid solution. The average corrosion rates were 18-20 mpy for unwelded and 27-32 mpy for welded specimens. This posed a difficult problem in continuing the 


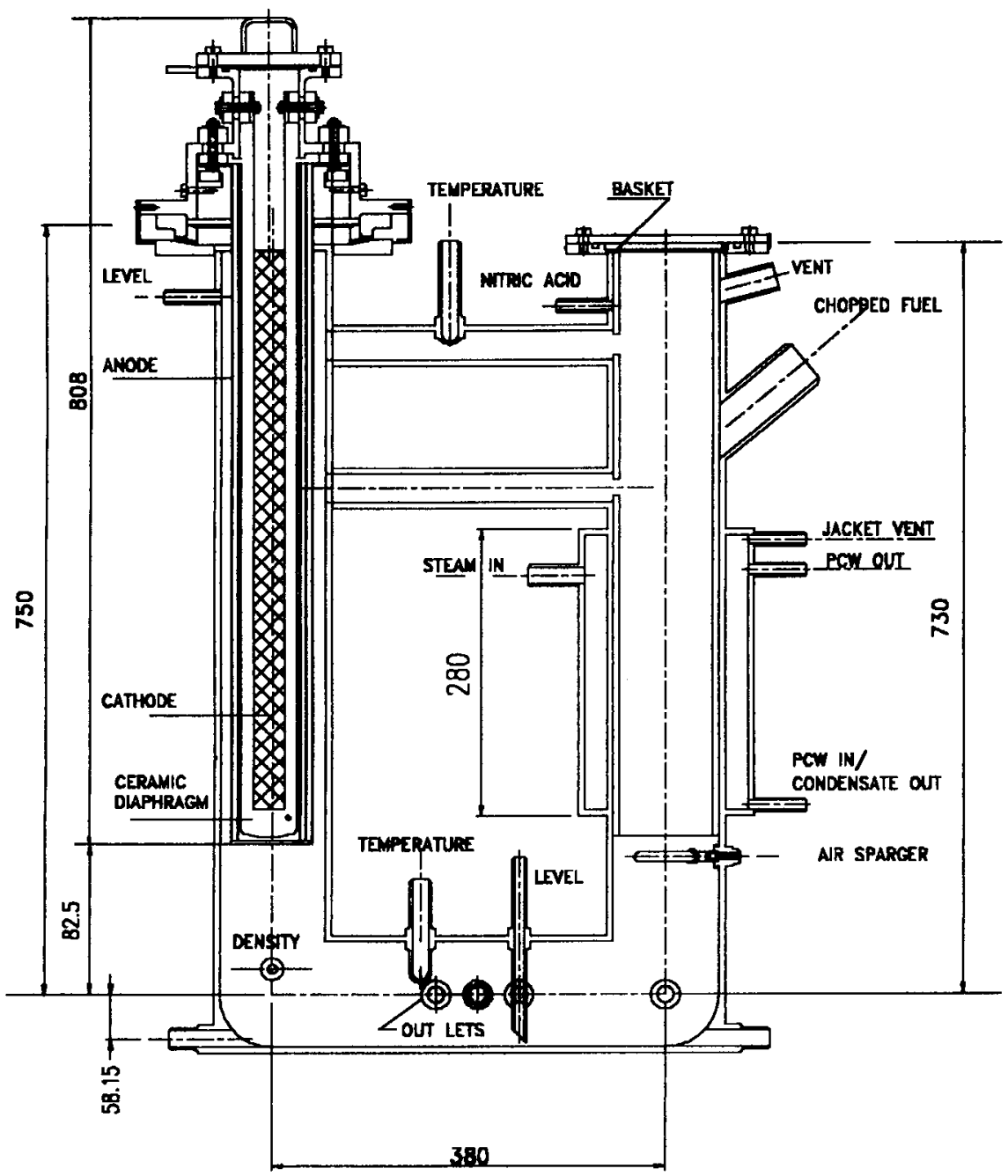

Figure 7. All-titanium electrolytic dissolver.

fabrication of the vessel ( $K$ amachi Mudali et al 2000). During the three-phase corrosion tests in $11.5 \mathrm{M}$ boiling nitric acid, it was found that corrosion rates of $20 \mathrm{mpy}, 0.88 \mathrm{mpy}$ and 5.65 mpy were exhibited by the material in liquid, vapour and condensate phases respectively. The high corrosion rates were attributed to the high iron content of titanium ( 0.05 to 0.1 ) which caused deleterious dissolution at the surface (IMI, Report). If the iron content was limited to less than $0.04 \mathrm{wt} \%$ (the solubility limit of iron in titanium), this could have been avoided. Hence, it was decided to establish a suitable surface modification procedure for improving the corrosion resistance of the material in both unwelded and welded conditions.

Considering that the surface treatment has to be implemented with the finished component in the plant, treatments like thermal oxidation, metal spraying, advanced coating technologies etc. could not be considered for this application. Anodisation is a unique way of forming a surface oxide layer that can distinctly enhance the corrosion 
Table 2. Average corrosion rate of titanium after surface treatment.

\begin{tabular}{lccc}
\hline & \multicolumn{2}{c}{ Electrolysis parameters } & \\
\cline { 2 - 3 } Test condition & $\begin{array}{c}\text { Potential } \\
\text { (V) }\end{array}$ & $\begin{array}{c}\text { Duration } \\
\text { (h) }\end{array}$ & $\begin{array}{c}\text { Average corrosion } \\
\text { rate in Huey } \\
\text { test (mpy) }\end{array}$ \\
\hline Conc. nitric acid & 10 & 0.5 & 19 \\
$10 \%$ Sulphuric acid & 12 & 100 & 18 \\
$10 \%$ A mmonium persul phate & 5 & 50 & 18 \\
$10 \%$ A mmonium persulphate & 12 & 50 & 16 \\
$10 \%$ A mmonium sulphate & 12 & 100 & 24 \\
(i) Nitric acid +1 ml HF $+30 \mathrm{mg} \mathrm{Ru}$ & 5 & 24 & \\
+30 mg Cr ${ }^{6+}$, followed by & 12 & 20 & \\
(ii) $10 \%$ ammonium persulphate & 5 & 24 & \\
(i) Nitric acid +1 ml HF $+30 \mathrm{mg} \mathrm{Ru}$ & & & \\
$+30 \mathrm{mg} \mathrm{Cr}$, followed by & 12 & 50 & \\
(ii) $10 \%$ ammonium persulphate & & & \\
\hline
\end{tabular}

resistance of several metals and alloys (Hayfield 1973). However, it has been reported in the literature that upon anodisation in several chemical media, the corrosion resistance of titanium is not improved significantly (Thomas 1986). Still, an attempt was made to develop a surface modification technology that could increase considerably the corrosion resistance of titanium in both unwelded and welded conditions, and can be used in the plant for the fabricated dissolver vessel. The main points considered in this development are: (i) a method to dissolve the iron particles segregated/enriched at the surface using chemical solutions by simple immersion; (ii) application of redox ion containing nitric acid based solution that can enhance anodic oxidation for forming a stable oxide layer; (iii) further stabilisation and growth of oxide layer in an alternate chemical solution; and finally (iv) conditioning of the surface film. The highlight of the technique is that the electrolytic dissolver fabricated and erected at the plant site can be surface treated by this method as it does not involve any complicated methods. Several chemical treatments were attempted for improving the corrosion resistance. A fter surface treatments, the specimens were tested as per ASTM A 262 practice $\mathrm{C}$ test in boiling $11.5 \mathrm{M} \mathrm{HNO}_{3}$ solution for five successive periods of $48 \mathrm{~h}$. Table 2 shows the average corrosion rate obtained for specimens under different surface treatment conditions. A mong all the treatments, anodising for $24 \mathrm{~h}$ in a solution of nitric acid containing $\mathrm{Ru}, \mathrm{Cr}$ and $\mathrm{HF}$, and subsequent anodic treatment in a solution of $10 \%$ ammonium persul phate gives the best results. The corrosion rate reduces to about 4 and 6 mpy in the Huey Test. This test procedure has been named DOCTOR (Double Oxide Coating on Titanium for Reconditioning), and is presently used for surface modification of dissolver made of titanium (Kamachi Mudali et al 2000).

\subsection{Development of dissimilar joints between titanium and AISI type 304L SS}

In the reprocessing plant, the electrolytic dissolver unit (figure 7) has to be connected to the rest of the process vessels and equipment made of AISI type 304L SS through a Ti/AISI type 304L SS dissimilar metal weld (DM W) joint. Fabrication and qualification of this DMW joint is crucial in the reprocessing plant especially because of zero failure requirements. Two solid-state welding processes, viz. explosive bonding and friction welding, were employed for fabricating this DM W joint to achieve adequate mechanical 
Table 3. Results of non-destructive, mechanical and corrosion tests.

\begin{tabular}{|c|c|c|c|c|}
\hline Tests & \multicolumn{2}{|c|}{$\begin{array}{l}\text { Friction welded } \\
\text { joint }\end{array}$} & \multicolumn{2}{|c|}{$\begin{array}{l}\text { Explosive bonded } \\
\text { joint }\end{array}$} \\
\hline $\begin{array}{l}\text { Non-destructive tests } \\
\text { Liquid penetrant test } \\
\text { Radiography } \\
\text { Ultrasonic test }\end{array}$ & \multicolumn{2}{|c|}{$\begin{array}{l}\text { Passed } \\
\text { Passed } \\
\text { Passed }\end{array}$} & \multicolumn{2}{|c|}{$\begin{array}{l}\text { Passed } \\
\text { Passed } \\
\text { Passed }\end{array}$} \\
\hline Mechanical tests & Test 1 & Test 2 & Test 1 & Test 2 \\
\hline $\begin{array}{l}\text { Tensile tests } \\
\text { Ultimate tensile streangth ( } \mathrm{MPa}) \\
\% \text { Elongation }\end{array}$ & $\begin{array}{c}462 \\
\text { Negligible }\end{array}$ & $\begin{array}{c}495 \\
\text { Negligible }\end{array}$ & $\begin{array}{l}397 \\
21.4\end{array}$ & $\begin{array}{c}457 \\
19.7\end{array}$ \\
\hline $\begin{array}{l}\text { Bend tests } \\
\text { Root bend (bend angle at failure) } \\
\text { Face bend (bend angle at failure) }\end{array}$ & $\begin{array}{l}<5^{\circ} \\
<5^{\circ}\end{array}$ & $\begin{array}{l}<5^{\circ} \\
<5^{\circ}\end{array}$ & $\begin{array}{l}60^{\circ} \\
80^{\circ}\end{array}$ & $\begin{array}{r}76^{\circ} \\
106^{\circ}\end{array}$ \\
\hline $\begin{array}{l}\text { Three-phase corrosion tests } \\
\text { Liquid phase (avg. corrosion rate) (mpy) } \\
\text { Vapour phase (avg. corrosion rate) (mpy) } \\
\text { Condensate phase (avg. corrosion rate) (mpy }\end{array}$ & & & & \\
\hline
\end{tabular}

properties and corrosion resistance (Tender Document 1997; A nanda Rao et al 1999). B oth the friction-welded and explosive-bonded pipe joints were non-destructively examined using liquid penetrant, radiography and ultrasonic testing. B oth joints passed all the NDT tests as no significant deviations from specifications were observed by the techniques (table 3).

Three-phase corrosion tests were conducted in $11.5 \mathrm{M}$ boiling nitric acid for specimens obtained from both the joints. The test involved exposure of the specimens to the liquid, vapour and condensate phases of the boiling nitric acid medium for 5 periods of 48 hours each followed by measurement of the corrosion rates in each of the three phases. Table 3 gives the average corrosion rates, in mpy, in the three phases. It was observed that, for both the joints, corrosion rates in the condensate phase are markedly higher than in the other two phases. Detailed optical and scanning electron microscopy (Kamachi Mudali et al 1999) examination of specimens exposed to the condensate phase indicated severe corrosion attack of the friction-welded joint with wide opening at the interface (figure 8a). The explosive-bonded joint had severe corrosion attack on the AISI type $304 \mathrm{~L}$ SS with selective attack at the vortex region of the interface (figure 8b). It was also observed that the average corrosion rate of the explosive-bonded joint in all the phases, except the liquid phase, is marginally higher than the friction-weld joint (table 3). However, the corrosion was localised at the interface of the friction-welded joint with the formation of a trench. Hence the corrosion rate is attributed to the loss in material at the joint interface. In the case of the explosively wel ded joint, the interface was free from corrosion, and severe corrosion was seen only at the AISI type 304L SS side of the joint. Further, corrosion attack was also found at the vortex region of the joint. Hence, corrosion rate could be attributed to the corrosion of AISI type 304L SS while maintaining the joint interface in good condition. Thus, explosively welded joints are more reliable compared to friction-welded joints with respect to corrosion. Microhardness measurements were carried out across the Ti/AISI Type 304L SS interfaces of both the joints at intervals of $500 \mu \mathrm{m}$ using a load of $200 \mathrm{~g}$. It 


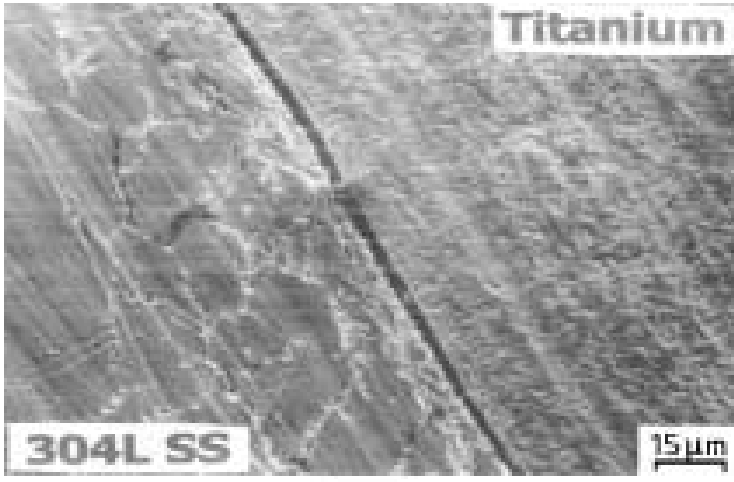

(a)

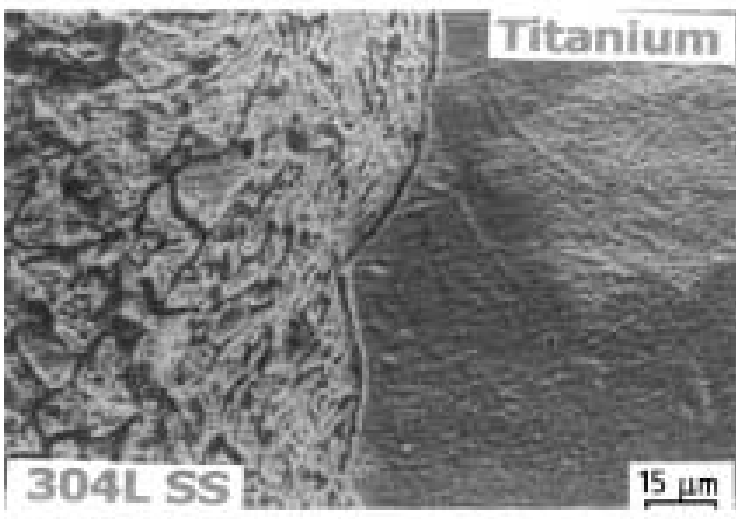

(b)
Figure 8. SEM micrographs showing (a) corrosion attack leading to trench formation at the interface of friction welded joint, and (b) corrosion attack on AISI type 304L SS side of the explosively welded joint.

was observed that the hardness of AISI Type 304L SS near the interface increased by only about 50 VPN for the friction-welded joint compared to that of about 250 VPN for the explosive-bonded joint. The high hardness of the AISI type 304L SS near the interface in the explosive-bonded joint can be attributed to the high degree of deformation/cold working of the SS surface during the explosive cladding operation. On comparison of the results of the various tests given in table 3 , it can be seen that the explosive-bonded joint has significantly better bend and tensile ductility than the friction-welded joint, with the other properties being comparable for both the joints. Since the joint did not have enough ductility (only $80^{\circ}-100^{\circ}$ bend was obtained as against $180^{\circ}$ bend in the guided bend test), it was decided to have an additional outer Ti-Ti-A ISI 304L SS sleeve over the dissimilar joint to protect it from stresses and strain. The Ti-A ISI type 304L SS joint design is shown in figure 9. In addition to catering to the needs of strength requirements, the provision of the Ti-Ti-A ISI type 304L SS sleeve would further provide extra corrosion allowance to the joint area. Since the titanium to titanium welding is close to the bonded area, additional precautions were taken, such as: (1) providing a copper sink over the clad area for absorbing the heat and thus avoiding the opening up of the bonded area, (2) following the sequence of machining, welding and boring as shown in figure 9 to absorb the heat, and 


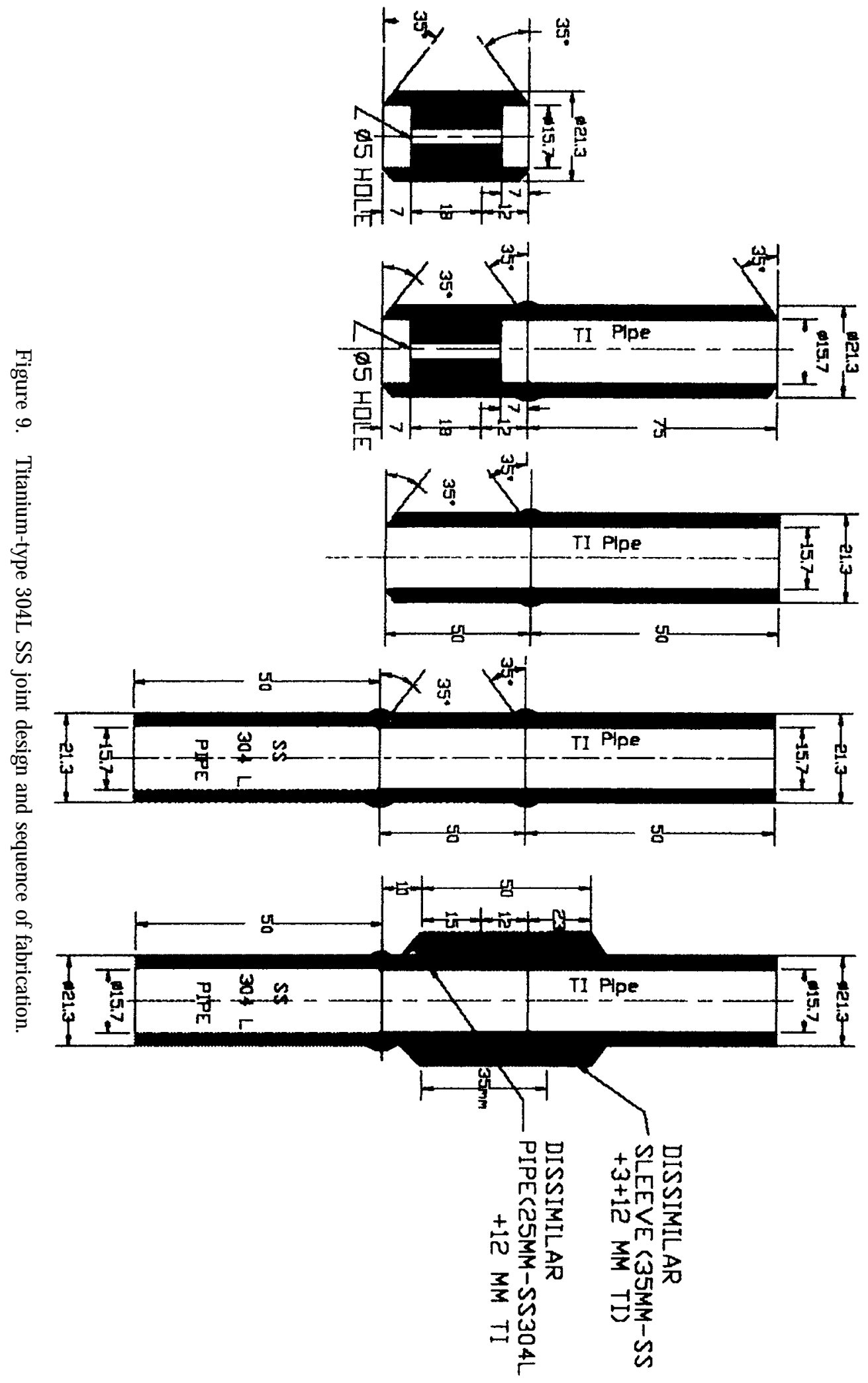


(3) carrying out segment by segment welding, and after each segment and each pass of the welding, bringing the temperature down to room temperature as quickly as possible by forced air circulation cooling. After stages 2 and 3 in figure 9, the DMW joint was inspected for radiography, fit up, visual and liquid penetrant examinations for ensuring that specifications were met.

Based on the results of the extensive investigations carried out, and considering corrosion resistance as the most critical requirement, the explosive-bonded titanium/AISI type 304L SS joint was chosen for connecting the titanium dissolver with other AISI type 304L SS process vessel piping. The importance of interdisciplinary work, approach to solving problems and the bold approach to achieving extraordinary fitness of purpose have lead to the completion of this critical job of fabricating the all-titanium dissolver and its associated piping system.

\subsection{J oint design for erection of titanium dissolver in the stainless steel containment box of the cell}

Since titanium cannot be welded directly to AISI type 304L SS, a method had to be evolved for the erection of titanium equipment in AISI type 304L SS containment box of the cell. The welding of titanium equipment to SS by appropriate design is a preferred one instead of mechanical fastening as welding avoids reduction of vacuum in the box which is al ways maintained at a higher negative pressure as compared to the cell space. Welding operation also prevents the leakage of liquid from the containment box, whereas the same is not guaranteed with mechanical fastening. Figure 10 shows the joint design for the erection of the dissolver in the SS containment box. A $6 \mathrm{~mm}$ Ti Grade 1 plate was cladded with $12 \mathrm{~mm}$ 304L SS plate, and then was machined and welded to the top flanges of the dissolver. It is essential that while welding the cladded ring to the dissolver flange at the bottom, it must be welded segment by segment. In addition, the welded segment is cooled to room

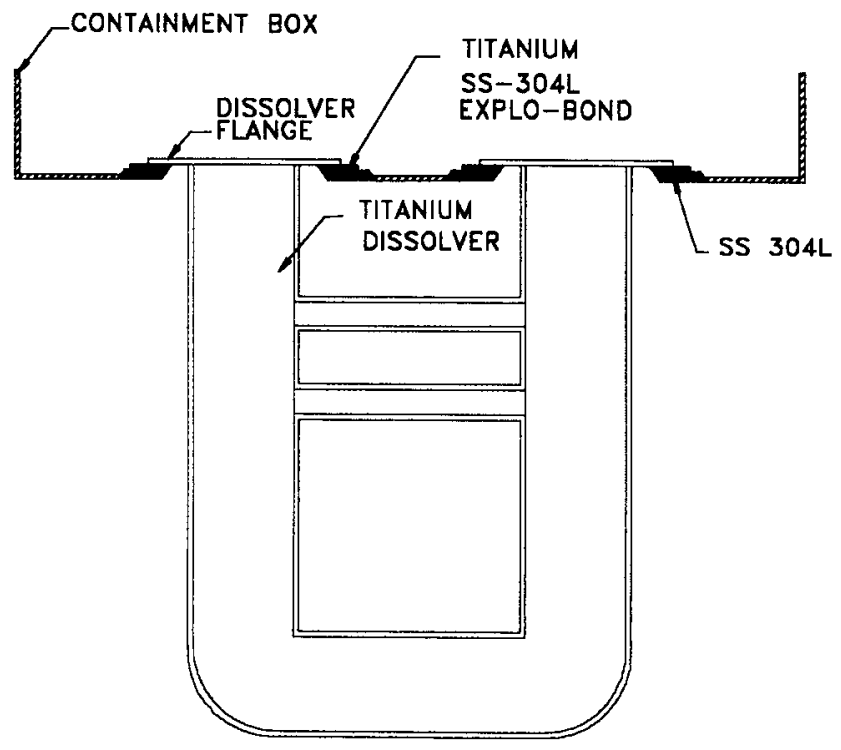

Figure 10. Joint design for the erection of all-titanium electrolytic dissolver. 


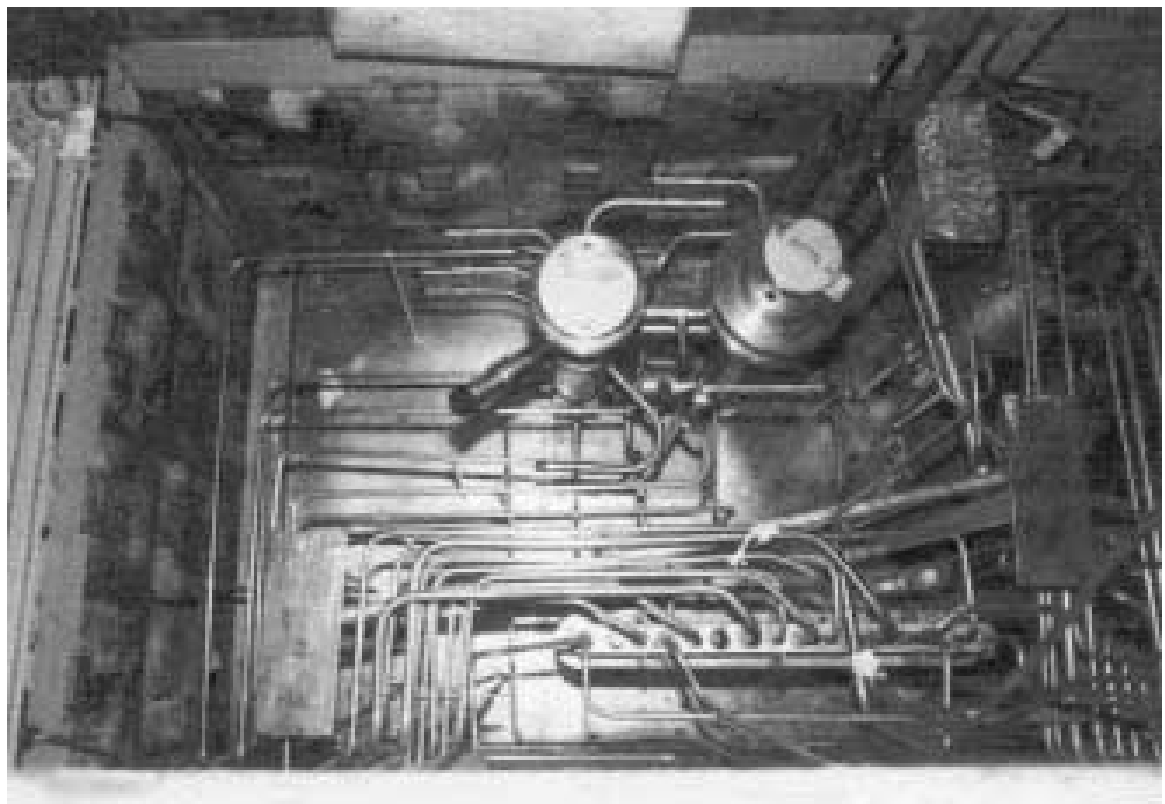

Figure 11. Photograph showing titanium dissolver assembly with piping.

temperature to avoid overheating of the cladded portion which otherwise may lead to opening up of the bonded area. A completely fabricated and erected electrolytic dissolver system for the dissolution of the spent fuel from FBTR at the operating area of the Reprocessing Group is shown in figure 11.

\subsection{Electrode materials for electrolytic dissolution of spent nuclear fuel}

Electrochemical methods are some of the promising ways of dissolving and purifying the spent nuclear fuel from the nuclear reactors, as compared to the conventional chemical methods (Palamalai et al 1991). The success and current efficiency of the electrochemical processes mainly depend on the durability or the corrosion resistance of the electrodes, the electrocatalytic activity or the low over-voltage for the desired rate-determining electrochemical reaction, and high conductivity facilitating operation of the electrolytic cell at high current densities. In addition, to achieve minimum interruption to the operation, and to avoid the risk in frequent replacement or addition of new electrodes in a radioactive environment, long life of electrodes used is of paramount importance while choosing an appropriate electrode for the electrolytic dissolution of spent fuel from FBTR. Currently, platinum metallic electrodes are being used for the above applications. However, platinum undergoes corrosion at high current densities of operation in nitric acid medium at high temperature (Baumgartner \& Schmieder 1978). Moreover, platinum is expensive considering the cost involved in running the plant with many unit operations, and failed platinum electrodes in a highly contaminated state cannot be refabricated for further use. These aspects have necessitated the development of economical platinised el ectrodes with corrosion resistant substrates providing high efficiencies at par with those of platinum electrodes for effective use in the plant. 
At IGCAR, Kalpakkam, initially commercially available titanium substrate insoluble anodes (TSIA) were tested for electrolytic dissolution of UC in concentrated nitric acid solution. TSIA electrodes failed beyond $338 \mathrm{~K}$ of operation as the coatings have no stability and life in nitric acid medium. Mixed oxide-coated titanium anodes (MOCTA) were developed (Kamachi Mudali et al 1991, 1992) at IGCAR for the electrochemical processes used for dissolution and purification of the spent $(U, P u) C$ fuel from FBTR. The M OCTA electrodes are titanium substrate coated with $\mathrm{RuO}_{2}$ and $\mathrm{TiO}_{2}$, with or without an overlay of $\mathrm{PtO}_{2}$. These electrodes belong to the category of 'Dimensionally Stable A nodes (DSA)' and find significant applications in fuel cells, cathodic protection, chlor-alkali production, electrowinning of metals, electrolytic production of manganese dioxide, electrochemical machining, electrodialysis and desalination. MOCTA electrodes were prepared by the thermal decomposition of solutions containing salts of $\mathrm{Ru}, \mathrm{Ti}$ and $\mathrm{Pt}$ applied over pretreated titanium substrate. It was found that the MOCTA electrodes worked up to the boiling point of concentrated nitic acid during electrolysis of a solution containing $72 \mathrm{~g} / \mathrm{l}$ of uranium ions. Further, these electrodes were used for a demonstration electrolytic dissolution of unirradiated mixed $(U, P u) C$ fuel of FBTR. These electrodes have worked satisfactorily for this purpose up to $20 \mathrm{~h}$ with constant cell potential-current behaviour. The life evaluation of the MOCTA electrodes exhibited steady potential and current up to $215 \mathrm{~h}$ at an operating current density of $6.5 \mathrm{~mA} / \mathrm{cm}^{2}$ during electrolysis in a simulated uranium containing boiling concentrated nitric acid solution (figure 12). For improving the life and performance of fine grained $\mathrm{PtO}_{2}$, overlaid MOCTA were subsequently prepared. Platinised MOCTA with an overlay of $\mathrm{PtO}_{2}$ worked satisfactorily up to $230 \mathrm{~h}$ at a current density of $9 \mathrm{~mA} / \mathrm{cm}^{2}$ under similar testing conditions (figure 12). It should be mentioned here that no commercially available similar oxide coated electrode materials worked beyond $338 \mathrm{~K}$ during electrolysis. Recently, MOCTA electrodes have been prepared with an intermittent conductive rutile- $\mathrm{TiO}_{2}$ layer and conventional $\mathrm{RuO} \mathrm{O}_{2}-\mathrm{TiO}_{2}$ coating, by applying plasma oxidation process (Kamachi M udali et al 1999). This produced

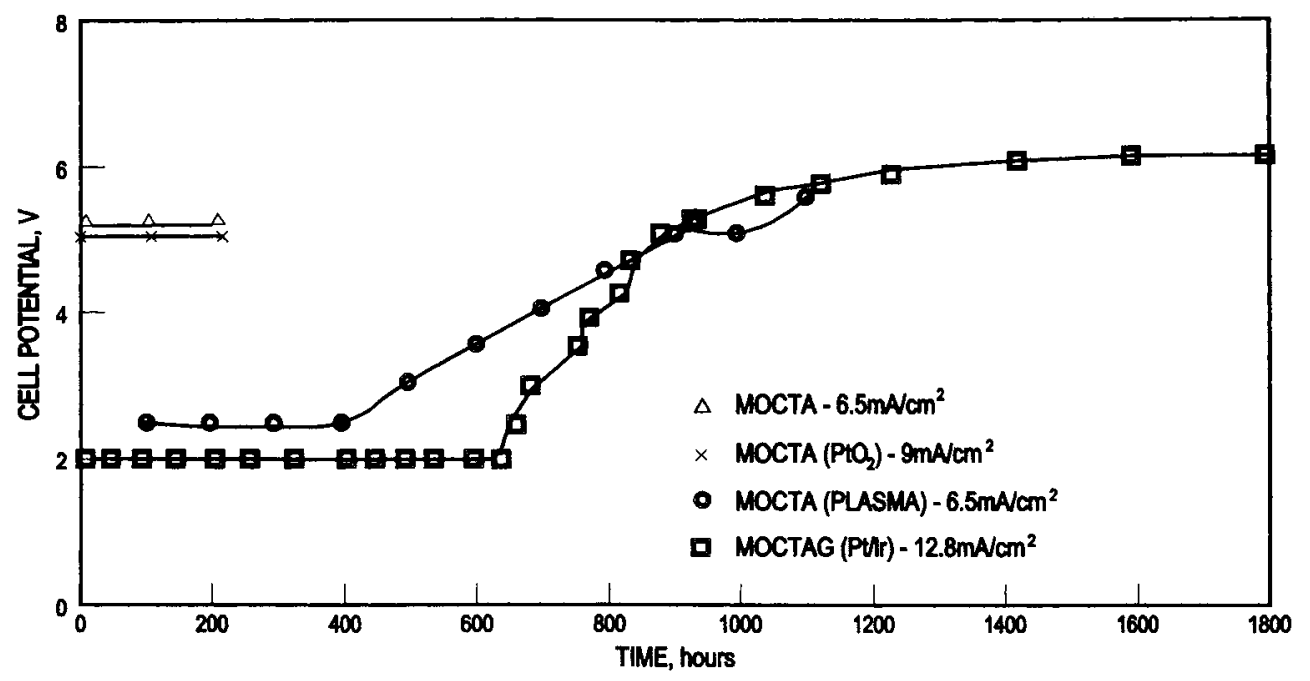

Figure 12. Life evaluation of various electrode materials in simulated boiling reprocessing solution containing nitric acid. 

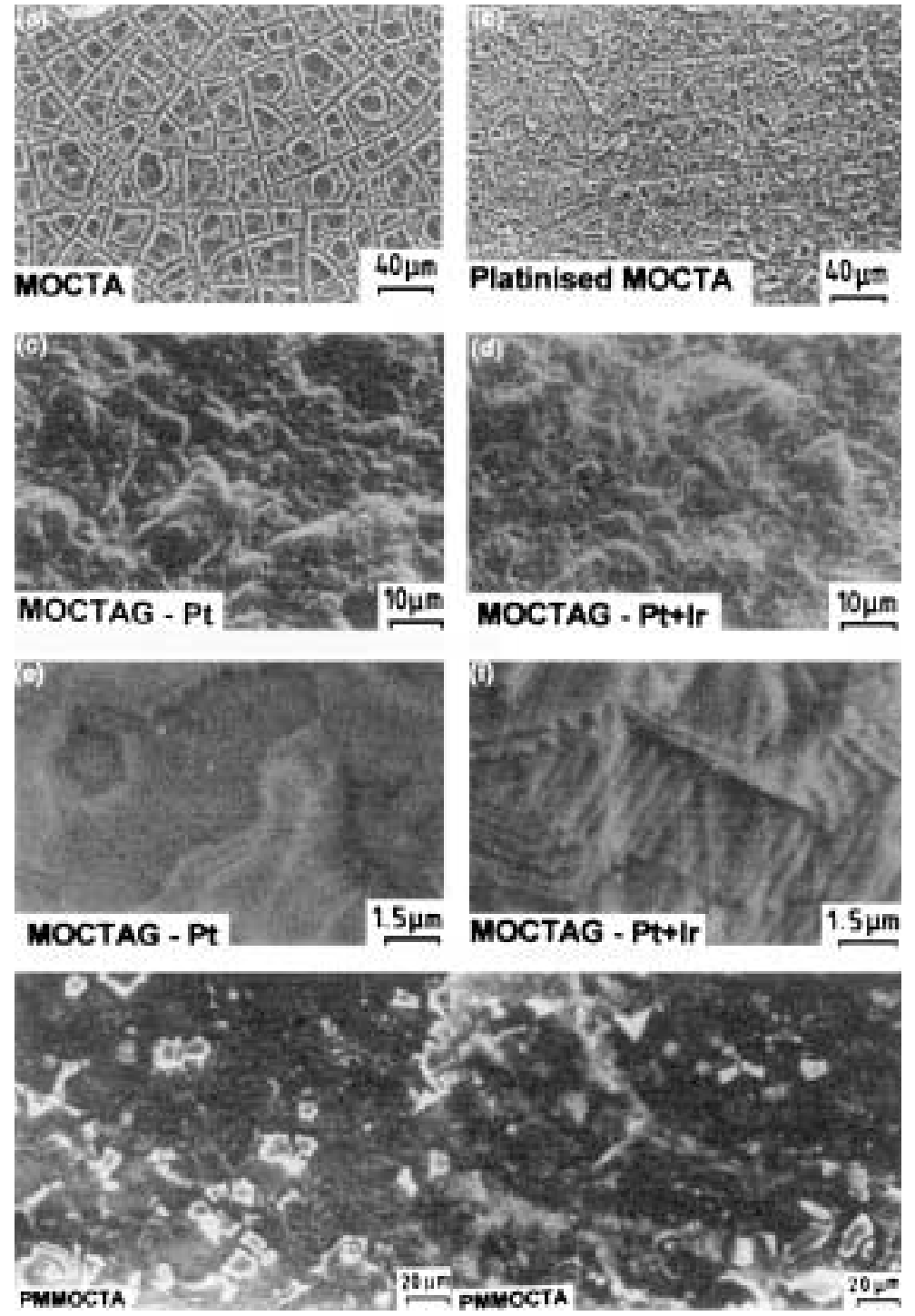

Figure 13. SEM morphology of various electrode coatings on titanium.

plasma-modified M OCTA (PM M OCTA) electrodes with smooth and compact coating of oxides (figure 13), with an excellent life of $1460 \mathrm{~h}$ during electrolysis in a boiling nitric acid solution (figure 12).

To increase the life of the electrode coatings, a new approach was made to develop metallic coatings on $\mathrm{Ti}$ substrate. Platinum and Pt-Ir coatings were prepared by 'thermochemical glazing' process on titanium substrates with intermittent $\mathrm{RuO}_{2}$ and $\mathrm{TiO}_{2}$ layers, and these electrodes are called 'MOCTAG' (Kamachi Mudali et al 1997, 1999). It was found that M OCTAG electrodes showed better electrochemical performance in comparison with Pt sheet electrodes. Life assessment of these electrodes in a simulated 
reprocessing boiling nitric acid (10 N) test solution containing uranium and other redox ions showed excellent performance of the Pt-Ir layered electrode up to $1850 \mathrm{~h}$ at $12.8 \mathrm{~mA} / \mathrm{cm}^{2}$ without any failure (figure 12). 'MOCTAG' electrodes produced by this method possess higher electrocatalytic activity at the surface, with better adherence of the coating in comparison with conventional MOCTA electrodes.

4. Nondestructive testing technology - development of techniques and methodologies for critical applications

For the successful operation of any chemical plant, it is mandatory to check the quality of the components at various stages starting from the manufacturing stage to online condition monitoring during operation in the plant. It is easier to apply various techniques and methods to study the different types of defects that are present in the component during the manufacturing stage as there is less constraint in doing the investigation. Several international and national standards are available for routine inspection of conventional components. However, for the quality evaluation of critical components like the heat exchangers operating at high temperature and pressures in a chemical plant, special techniques and procedures are necessary for achieving requisite quality levels. Thus, it is important that newer techniques that provide reliability and sensitivity in detection of the defect and its qualification are developed. Such developments can happen only if the understanding of the problem is clear and knowledge for analysing such data is available. The problem of studying the quality of the components while they are in service is very complicated and challenging due to various constraints. However, a study of the overall health of the plant is essential in order to avoid catastrophic failure of critical components, to locate defects in the component, to analyse the growth or survival of such defects leading to final failure, to arrive at a possibility for repairing of such defects, and if repaired, for further growth or survival of such defects, and finally to get information about the remaining life of the components having such defects. These challenges are worthwhile as these ensure keeping the component/plant in good health, and help in conserving the special materials and the capital.

Non-destructive evaluation (NDE) technology has been mastered with excellence in our country in the last decade, and has contributed significantly in improving the quality of fabricated components and condition monitoring of components in service (Baldev Raj \& Jayakumar 1997; Baldev Raj \& K asiviswanathan 1997). In the area of damage assessment, life extension and management of components and plants, work has gained importance as some of the plants are approaching the end of their design lives. The Indian nuclear industry has from its inception, adopted stringent quality control measures and technologies during fabrication of components, systematic planning and implementation of in-service inspection (ISI) programmes for condition assessment of critical components and structures (Rodriguez \& Baldev Raj 1997). Necessary expertise, techniques and procedures have been developed indigenously to meet the challenging demands of stringent specifications during fabrication, and pre-service and in-service inspection requirements. L ife management of a nuclear power plant in reality begins at the component manufacturing stage itself (Srinivasan $\&$ Prasad 1994). A dequate and stringent attention to quality assurance procedures at the fabrication stage can significantly enhance the life of the component and the plant as a whole. A few of the significant developments related to improved quality assurance of a few critical components used in nuclear power plants are described. 


\subsection{D evelopment of techniques for quality assurance at fabrication stage}

4.1a Inspection of thin walled cladding tubes: NDE methods have been developed and standardised for stringent quality control of the fuel cladding tubes of fast reactors (AISI type 316 SS (VIRGO 14 SB), $5.1 \mathrm{~mm}$ outer diameter and $370 \mu \mathrm{m}$ thickness), which are some of the most critical components in the core of a reactor. A merican Society for Testing and M aterials (ASTM ) standard A 771 gives guidelines on the mandatory use of ultrasonic testing for inspection of austenitic stainless steel tubing for breeder reactor core components. However, studies made at Indira Gandhi Centre for Atomic Research (IGCAR), Kalpakkam, have clearly demonstrated that both ultrasonic testing (UT) and eddy current testing (ECT) should be considered complementary techniques and are essential for use on finished tubes. Tubes having defects less than $7 \%$ wall thickness were accepted. The significant percentage of unacceptable tubes based on eddy current testing, after their acceptance by UT, underscored the importance and the essential nature of eddy current testing for pre-service quality control. Random checks by metallography indicated that defects other than inclusions detected by UT and/or ECT were dependent on their orientation (longitudinal/circumferential). ECT also detected localised dispersion of fine inclusions, which were missed by UT. While developing fabrication procedures for indigeneous production of cladding tubes, "banding" of the tubes (periodic wall thickness variations) was observed. Eddy current testing of tubes with banding was found to be difficult due to interference of noise from banding. Systematic developmental studies on the feasibility of defect detectability in cladding tubes with banding have been carried out with various approaches, including conventional single frequency eddy current testing (SFECT), multi frequency ECT (MFECT), phased array ECT (PAECT), deconvolution of conventional signals and the use of artificial neural networks (ANNS). PAECT detected all the artificial defects with a good signal-to-noise ratio (SNR). Since the use of PAECT requires special instrumentation and probes, al ternative approaches using deconvolution methods and ANN approaches were studied and were found to perform well for reliable inspection of banded cladding tubes with scope for automation on the shop floor (Shyamsunder et al 2000). Figure 14 shows the correlation between A N N output and defect size obtained using a reference cladding tube with artificially introduced through-andthrough holes. The use of defect-free cladding tubes avoids failures of fuel pins and thus the release of radioactivity into the coolant. This aspect results in significant confidence in operation of the reactor and savings in life management of reactor systems.

4.1b Q uality assurance of tube-to-tube sheet-weld joints of steam generator assembly of fast reactors: The importance of high integrity welds in steam generators of fast reactors (2.25 Cr-1 M o steel, $17.2 \mathrm{~mm}$ outer diameter and $2.3 \mathrm{~mm}$ thickness) arises due to risks of sodium-water reaction in the eventuality of a break in the tube. Tube-to-tube sheet-weld joints are regions where the possibility of development of a leakage path is highest. Thus, extreme care is taken in the quality assurance of the joints. In this regard, two aspects are important: (a) control of weld defects (porosity), (b) use of proper post-weld heat treatment (PWHT) to get a stress-relieved weld with good resistance to caustic stress corrosion cracking and acceptable long term mechanical properties. A rod-anode based microfocal radiography technique has been developed with sensitivity for detection of single porosities of $40 \mu \mathrm{m}$ size. Acceptance specifications include: (i) no single pore of size $>0.4 \mathrm{~mm}$ be acceptable, (ii) diameters of all pores in a $3 \mathrm{~mm}$ diameter region not to 


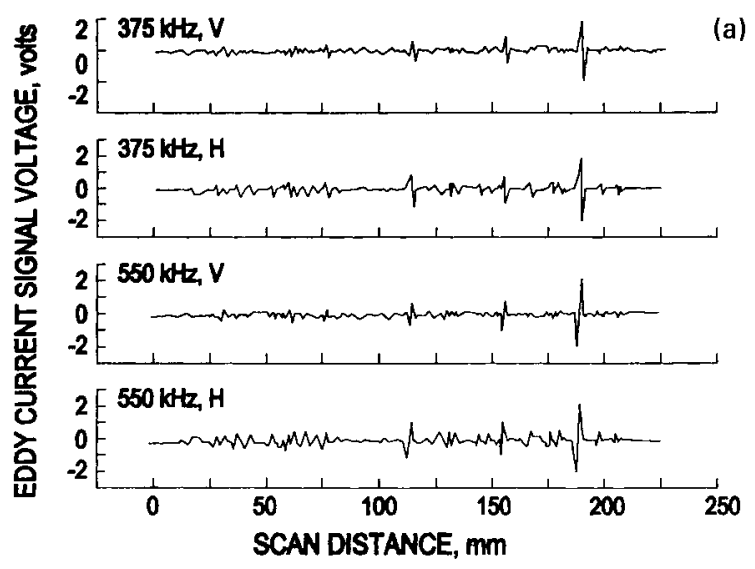

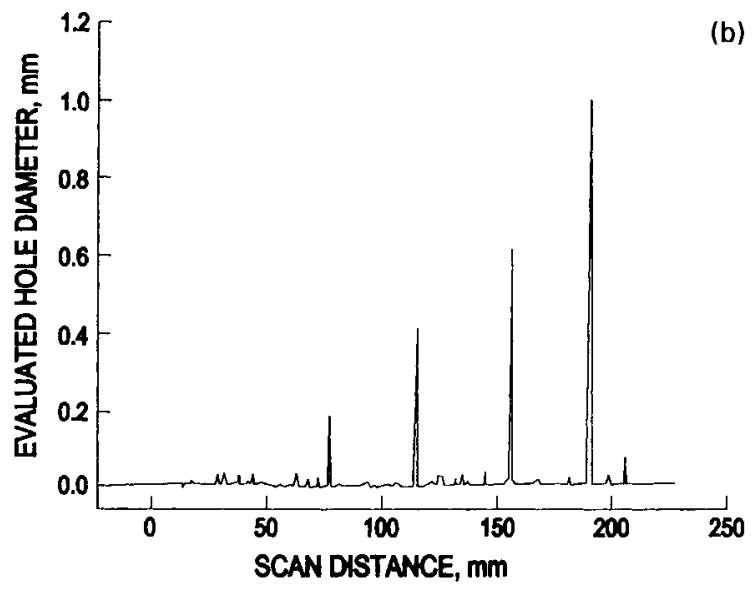

Figure 14. Correlation between the ANN output (a) and defect size (b).

exceed $0.6 \mathrm{~mm}$, and (iii) total pore count in the entire weld be such that the sum of diameters of all the visible pores be less than $2.54 \mathrm{~mm}$. These requirements necessitate high sensitivity defect detection in these welded joints (Rodriguez \& Baldev Raj 1997). The configuration of the weld joint is such that microfocal radiography with rod-anode is the only solution for examination of such welds. A backward throw probe with a diameter of $10 \mathrm{~mm}$ and with a beam spread of $-5 \times 55 \times 360^{\circ}$ was inserted from the tube sheet side and the radiography of the weld was carried out with a projective magnification of $3 \times$. A special radiographic cassette was designed and developed for this purpose. Results on the welds of these tubes have shown that it is possible to resolve a 30-40 micron diameter steel wire placed on the tube's internal diameter, which corresponds to $1.3-1.6 \%$ of the wall thickness of the tube. The results of the microfocal radiography studies were helpful for arriving at the correct weld parameters for an optimum weld joint.

It is often felt necessary to use a field worthy non-destructive testing (NDT) technique to check the adequacy of the PWHT employed in the large numbers of tube-to-tube sheetweld joints of steam generators. To meet this requirement, magnetic $B$ arkhausen noise (MBN) technique has been specifically developed at IGCAR. The MBN measurements 
were made so as to cover the weld, heat affected zone (HAZ) and base metal regions. A fter the measurements in the as-welded condition, the tubes were post-weld heat-treated at $973 \mathrm{~K}$ for $1 \mathrm{~h}$ and then air-cooled. The results showed that, in the as-welded condition, there was maximum MBN peak height at both ends (base metal region) and there was gradual reduction in peak height with decreasing distance from weld. The weld region showed the minimum MBN peak height. The large variation in the MBN peak height at different locations across the weld line indicated significant differences in the hardness in the weld, heat affected zone (HAZ) and base metal regions. After the PWHT, the MBN peak height becomes more or less the same at all the locations. These studies indicate the possibility of evolving an acceptance criterion based on the MBN peak height values to ensure the effectiveness of the PWHT (Baldev Raj \& Jayakumar 1997).

\subsection{Development and application of NDE methods for condition monitoring of nuclear power plant components}

Nuclear power plants are built with a conservative design life for safe and reliable operation. During the operating life of a nuclear power plant, components are exposed to influences whose single and combined effects cannot be predicted with the accuracy desirable for nuclear safety and life management (Baldev Raj 1994; Srinivasan \& Prasad 1994). The most important influences are stress, temperature, irradiation, vibration and fretting, and these result in changes of microstructure and material properties. $M$ anaging the operation of these plants with a well-designed programme for condition assessment through in-service inspection (ISI) and using time-tested approaches for life prediction, it is possible to extend the life of the nuclear power plants. Experiences have revealed that such life extension is a viable proposition and has enormous economic implications. Condition assessment through ISI and life prediction approaches would enable repair, upgradation, modernisation and replacement of necessary components and extension of the life of the remaining components and the overall plant well beyond the design life. To achieve this desired objective, there is a growing trend around the world to develop new methods, and to continuously upgrade the existing ones to ensure the high quality of fabricated components. The need to study the ageing phenomena in the context of condition assessment, life prediction and extension of components of the power plants is also of significance. Thus, in-service inspection becomes a necessity to detect any incipient failures, to avoid unplanned plant outages, and for effective life management.

4.2a NDE of components of boiling water reactors at Tarapur: The oldest power reactor in India is the Tarapur A tomic Power Station (TAPS) which has provided more than 25 years of service (the economic life of the reactor). Various components like the reactor dry well, reactor vessel, vessel internals, piping and pump casing (figure 15) undergo degradation in service and thus influence the decisions relating to life extension of the boiling water reactors (BWRs). The reactor dry well, which is a pear-shaped vessel connected to its own suppression pool, undergoes corrosion. During each refuelling outage, the thickness of the vessel is measured by ultrasonic testing to assess the extent of corrosion, as part of the condition assessment programme. The reactor vessel and the internals are subjected to irradiation embrittlement, irradiation-assisted stress corrosion cracking (IASCC) and fatigue. Coupons corresponding to the base metal, weld and HAZ of the reactor vessel kept at different locations of the vessel are removed at regular intervals to 


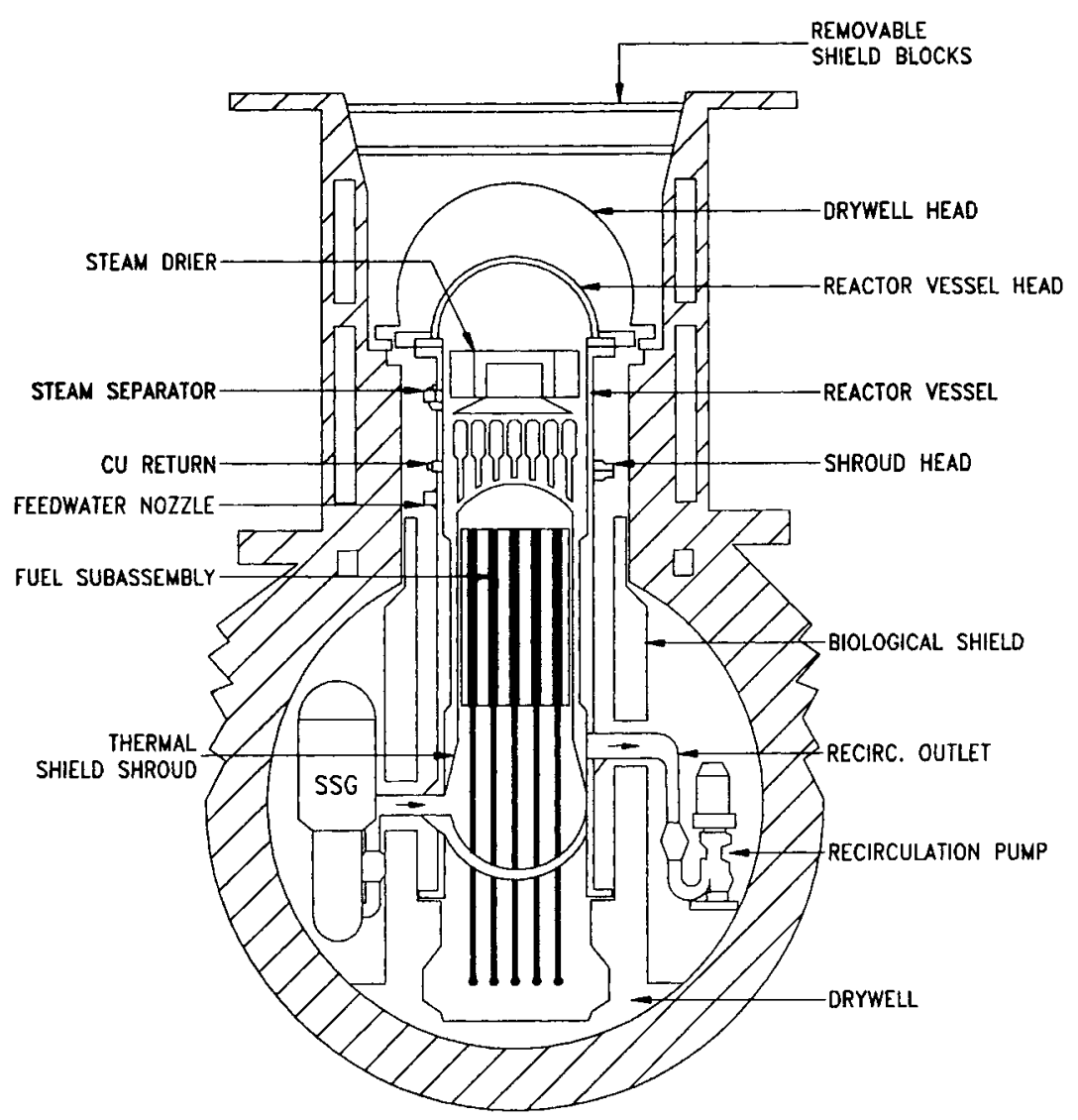

Figure 15. Schematic of BWR assembly with various components.

assess the extent of embrittlement in the vessel. The core internals including the core shroud are susceptible to IASCC. The main reactor recirculation piping and the rest of the primary pressure boundary are not made of the low carbon variety of stainless steel and hence are susceptible to intergranular stress corrosion cracking (IGSCC). U sing ultrasonic testing ISI is routinely employed to evaluate the IGSCC. Remedial measures like replacing the affected piping with nuclear grade low carbon variety stainless steel and also the new last pass heat sink welding process that mitigates IGSCC are adopted. The recirculation pump casing made of cast stainless steel is susceptible to thermal embrittlement. Periodic in-situ metallography is carried out to assess the degradation of microstructure (conversion of delta ferrite in the cast structure to sigma phase thus causing the embrittlement).

The core shroud (figure 16) in BWRs is a stainless steel cylinder, the top ring is welded to support the steam-dryer/separator assembly, and the bottom is welded with a flange to support the core bottom plate (B hasin 1998). The main function of the shroud is to separate the upward core flow from the downward flow via the annular space between the core and reactor vessel. The core shroud also provides a refloodable volume under postulated accident conditions and maintains core geometry. The stainless steel used for shrouds in most of the BWRs is of grades AISI type 304, 304L and 347, all of which are susceptible to 


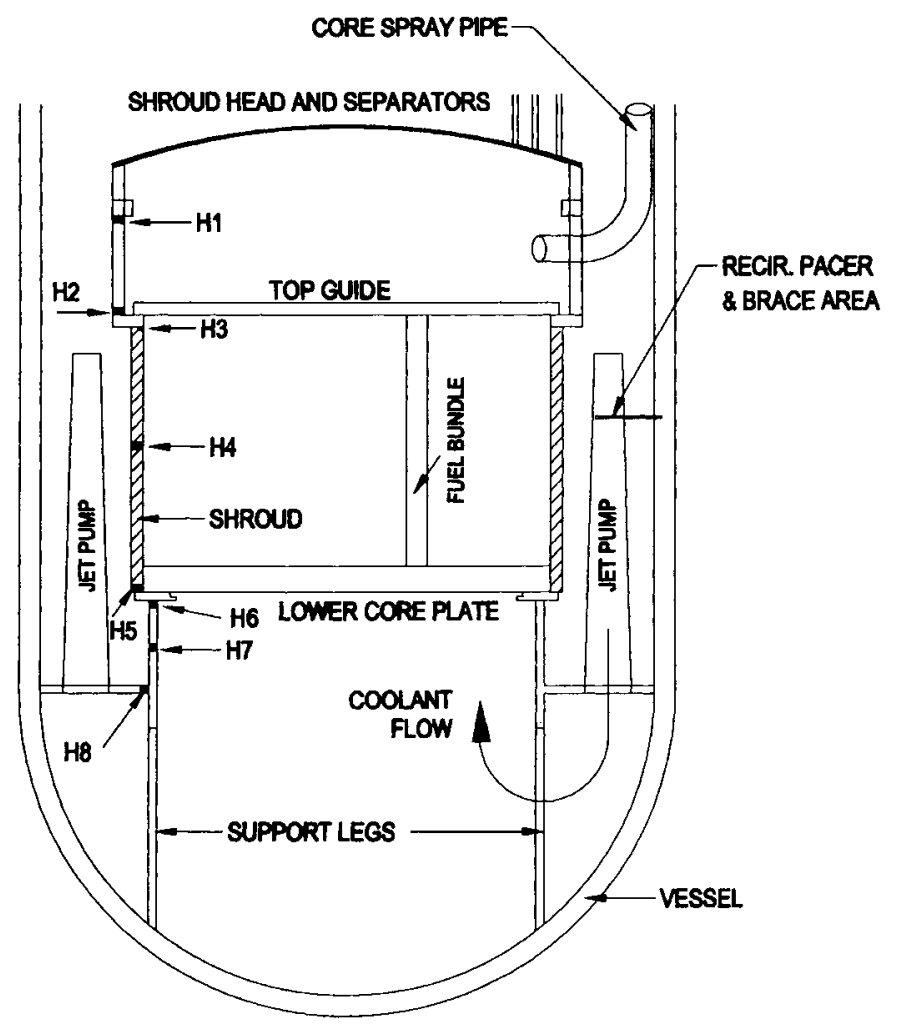

Figure 16. Diagram showing the structural configuration of core shroud.

IGSCC in the weld HAZ due to residual stresses and sensitisation introduced during wel ding processes. A dditionally, stresses are also introduced during machining of the plates for making the shroud and during fit up used for welding different components of the shroud. The operating environment of the BWRs, i.e. water with chlorides and oxygen provides the corrosive species needed for the occurrence of IGSCC in the shroud. Additionally, the radiation environment enhances the susceptibility for IGSCC of the shroud and this is referred to as IASCC, which normally occurs above a fluence value of about $5 \times 10^{20}$ neutrons $/ \mathrm{cm}^{2}$. The main inspection techniques employed are visual examination for location of the cracks and UT for detection of the cracks (which showed good correlation with the visual examination results) and for the determination of the depth of the crack. In order to quantitatively estimate the remaining period for which the structural integrity of the core shroud shall be maintained, conservative estimates of the depth of the existing cracks, the length of circumferential crack and the rate of crack growth are essential. Reference standard for visual inspection called sensitivity, resolution and contrast standard (SRCS) consisting of a representative portion of the shroud with reference defects in the area of interest are employed. The dimensions of the reference defects (wires) are $100 \mathrm{~mm}$ length and 12 or $25 \mu \mathrm{m}$ width. The reference defects should be introduced in the horizontal and vertical planes. To obtain more accurate and reliable information of the crack depth, an under-water ultrasonic inspection system is employed. Both visual and ultrasonic examination procedures have been developed jointly by BARC, NPCIL and IGCAR and successfully employed for detailed inspection of the core shrouds of the TAPS. 
$4.2 \mathrm{~b}$ Condition assessment of pressurised heavy water reactors (PHWRs): Both analytical methods and condition monitoring tools have been developed for assessing the safe operating life of the coolant channels that are the life limiting components of a PHWR. Figure 17 shows the general layout of the coolant channel assembly and the various components associated with them. An operating PHWR consists of 306 pressure tubes, made of zircaloy-2 in the earlier reactors. Subsequent to the failure of a pressure tube (PT) in the Pickering-2 reactor, in Canada in 1983, it was realised that the garter springs could get displaced during hot conditioning and/or during the operation of the reactor. This displacement increases the unsupported length of the PTs. This increase, coupled with the in-reactor creep of the PTs may make the outer surface of the PTs (with a maximum temperature of $548 \mathrm{~K}$ ) touch the cold inner surface of the CTs (with a temperature of $333 \mathrm{~K}$ ) leading to the formation of a cold spot and further, to the generation of massive hydrides through intense hydrogen diffusion to the cold spot region. This, in turn, may result in the formation of blisters and cracks leading to ultimate failure of the PT. In view of this, the structural integrity of the pressure tube needs to be considered not only with respect to its own properties, but together with the CTs and the garter springs as well. Special eddy
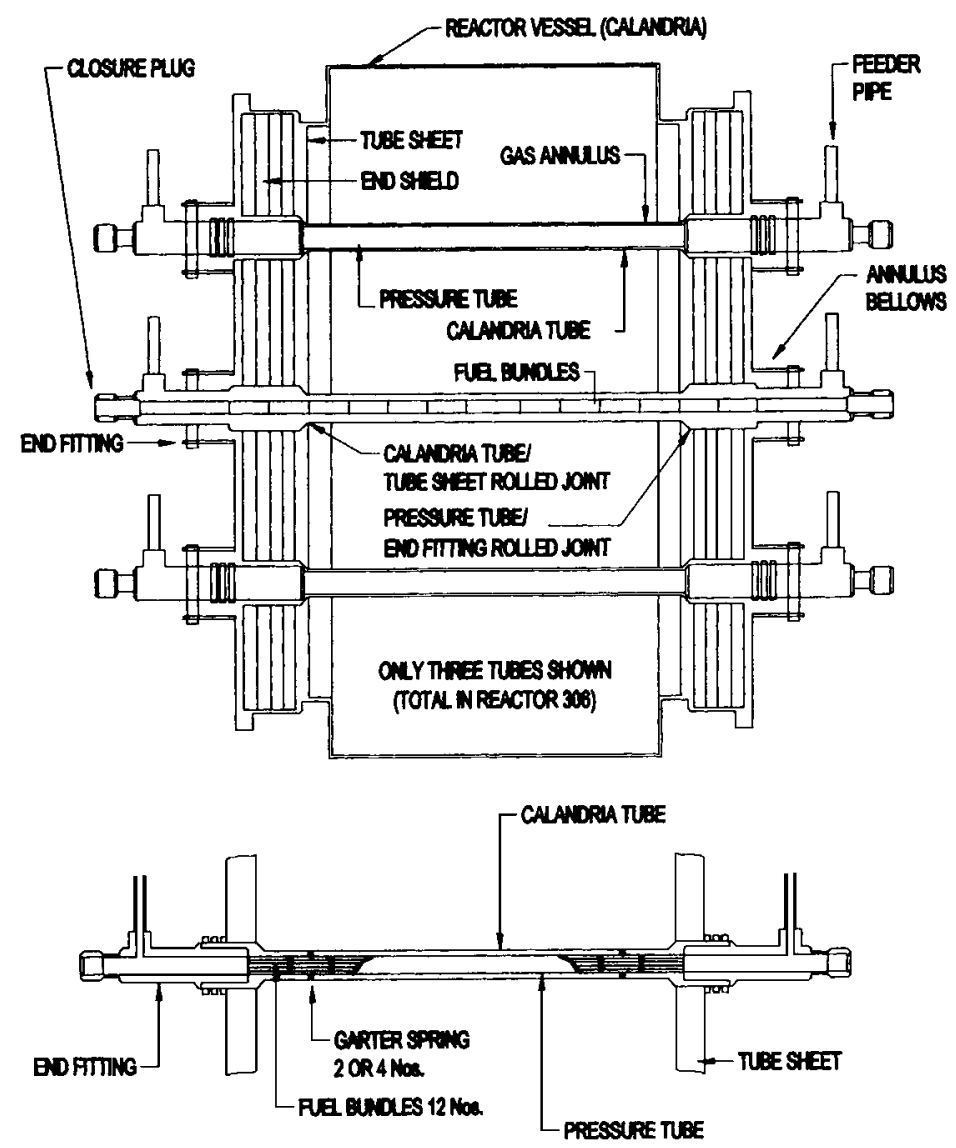

Figure 17. General layout of the coolant channels assembly and the associated components of a PHWR. 
current and ultrasonic testing probes and procedures have been developed with capabilities for performing ISI to obtain the following information: (i) Location of garter springs between PT and CT, (ii) profiling of the gap between PT and CT, and (iii) defect detection in PT. A finite element model has been developed and used to optimize probe design for garter spring locations. The accuracy of the garter spring location has been $\pm 5 \mathrm{~mm}$ and that of the gap profile is $\pm 0.5 \mathrm{~mm}$. D efect detection in the PTs is mainly concerned with the detection of localised hydride blisters, if any, along with other possible defects. In a fullscale mock-up assembly consisting of various artificial notches, a longitudinal notch of depth $5 \%$ of the wall thickness and a transverse notch of depth $8 \%$ of the wall thickness were detected unambiguously using the probes and methods developed. Remedies suggested for avoiding the problem of hydride blisters include: (i) Use of four springs instead of two in each channel, (ii) adoption of tight-fit garter springs made of Inconel $X 750$, (iii) replacement of all zircaloy-2 PTs of existing reactors with $Z r-2.5 \mathrm{Nb}$, (iv) retube of all channels having two garter springs with Zr-2.5 N b PTs with four garter springs, and (v) reposition garter springs with electromechanical devices. Further to the above developments, a completely automated coolant channel inspection system named BARCIS (Bhabha A tomic Research Centre Channel Inspection System) has been developed and commissioned by BARC, Bombay and has been successfully used at different PHWRs for various ISI campaigns ( $M$ anjit Singh et al 1994). The system is designed with the aim of minimising radiation exposure to inspection personnel and to minimise reactor downtime.

At IGCAR, a highly sensitive focussed eddy current probe has been developed to detect extremely fine defects of the order of scratches in the range of 50-75 microns (Kalyanasundaram et al 1998). This special probe was successfully utilised to detect the presence of scratches of depth greater than 50 microns in one CT of a PHWR, which had undergone PT replacement. Indigenous codes, systems and inspection methods have been developed for assessing the safe operating life of pressure tubes under the degrading effects of creep, hydriding and embrittlement. Continuous updating of the codes and methods based on ISI and post-irradiation examination (PIE) is also adopted.

4.2C Leak detection in pressure tubes of PHWRs: In a condition-assessment campaign undertaken in unit 1 of the Madras A tomic Power Station (M A PS), two possibly leaking pressure tubes among the 306 pressure tubes were detected using the acoustic emission technique (AET) utilising advanced signal analysis methods. Conventionally practised time-domain methods did not yield satisfactory results because of the poor signal-to-noise ratio of the leak signal. Plant personnel had observed heavy water leakage in the calandria vault. Investigations revealed that the leakage was from one of the 306 pressure tubes. AET was the only possible technique to identify the leaking pressure tube because of its potential for leak detection even in inaccessible locations by virtue of having direct acoustic contact between the likely leak location and the accessible part of the component/ system (K alyanasundaram et al 1992). The high background noise associated with leak signals, particularly due to operation of primary heat transport (PHT) pumps, did not permit the use of a simple and routinely used time domain parametric approach. A dditionally, the characteristics of the signals from different channels due to background noise were not similar and hence it was not easy to identify the leaking channel. Therefore, the first task was to segregate the channels with similar signal characteristics into different 
(a)

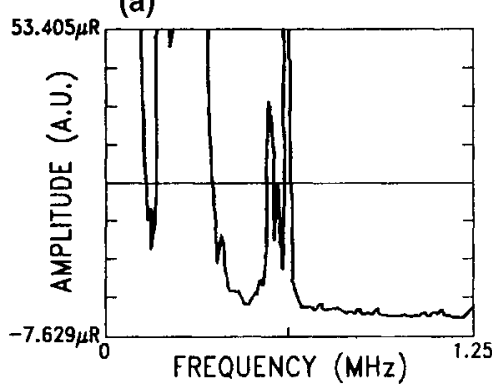

(c)

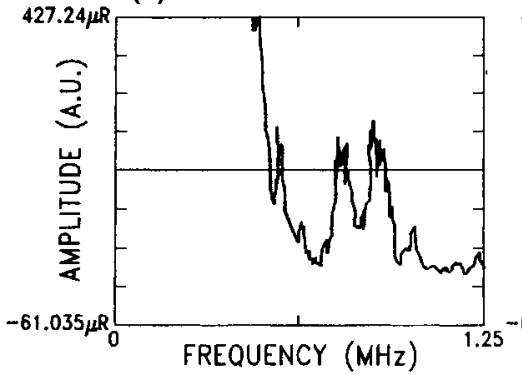

(b)

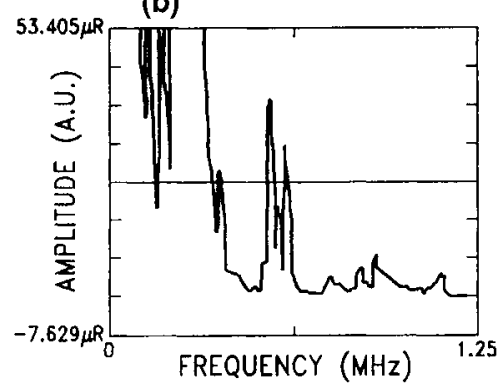

(d)

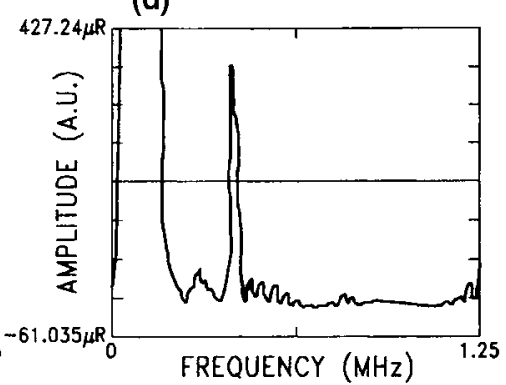

Figure 18. A uto power spectra from coolant channels of a PHWR: (a) healthy channel, (b) suspect leaky channel (sl. no. 1), (c) leaky channel (sl. no. 2), (d) possible seal plug leak (sl. no. 5).

groups from the spectral characteristics of the signals recorded for each channel (figure 18) and to select the group containing the suspected leaking channel. A ccordingly, a group of 15 channels were short-listed as the possible leaking channels from the 306 channels using the criterion that the leaking channel should have signals with frequencies above $200 \mathrm{kHz}$. The ratio of the spectral energy between two different frequency bands, namely 700 to $1000 \mathrm{kHz}$ and 40 to $175 \mathrm{kHz}$, and its variation with an increase in pressure were used to identify the suspect channels. For the two identified channels, this ratio increased with an increase in the pressure (Rodriguez \& Baldev Raj 1997). Subsequent investigations by the plant personnel using vacuum testing and hydro testing confirmed that one of the two channels identified by the AET had leakage of heavy water from the pressure tube.

4.2d Condition monitoring of end shields of Rajasthan Atomic Power Station (RAPS): One of the important systems of the PHWR is the end shield system. The end shield in RA PS is made of $3.5 \% \mathrm{Ni}$ steel. The end shield is used to prevent direct radiation field that comes from the reactor core region into the fuelling machine vault. The end shield consists of two tube sheets separated by lattice tubes. In order to remove the heat generated by radiation, water is circulated within the end shield system. Leaks have developed in the inaccessible tube sheet of the end shield i.e. calandria side tube sheet (CSTS). Special ultrasonic and acoustic emission procedures have been developed at IGCAR for successful detection, location and orientation of the cracks. Figure 19 shows the autopower spectra of the AE signals for (a) defect-free CSTS, (b) CSTS with one crack open to air leak, and 


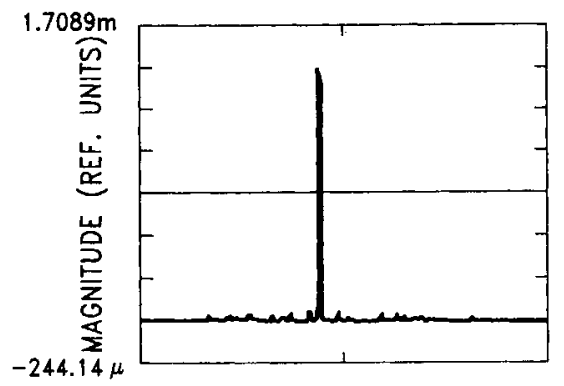

(a)

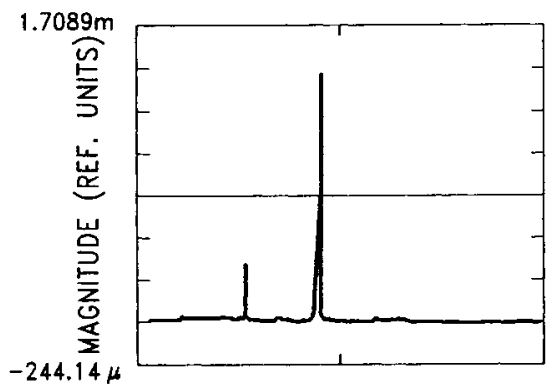

(b)

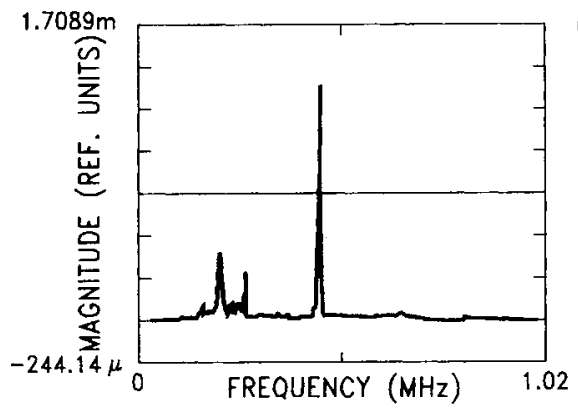

(c)

Figure 19. AET for leak detection in end shield of a PHWR: (a) background noise, (b) due to single leakage, and (c) due to multiple leakage.

(c) CSTS with two cracks open to air leak. Characteristic peaks corresponding to air leak from the two cracks can be seen in the autopower spectra (figure 19). This has enabled repair of end shield and continued operation of the reactor.

5. Failure analysis - critical tool for diagnosing material-related problems

In any chemical plant, failure of engineering components in service is a cause of concern as it may lead to loss of productivity and raise issues related to safety and reliability. Plant chemistry may be changed as the failure may cause mixing up of chemicals, process solutions etc. Downtime is extended beyond the time of the arrival of new component if there is no replacement available. Thus the failure of a component in the plant is an undesirable event for plant personnel, as this affects reliability and profitability, and also the morale of operating personnel. How ever, it is a fact that failures give very important 
information about the malfunctioning of the system, changes in material properties/ behaviour, operational manœuvers, design incompatibilities etc. A ny failure analysis is a delight for materials engineers as it often helps them to develop advanced technologies, and improved designs and materials modifications (ASM 1975, 1997; Baldev Raj \& Kasiviswanathan 1997). Thus, there has to be a good understanding and appreciation between the two ends of the spectrum, that is, concerns of the plant personnel and delight of materials scientists and engineers. The main failures in any chemical plant occur with major equipment like heat exchangers, condensers, pumps, vessels, reactors, evaporators/ concentrators etc. which decide further availability of the plant for useful purposes. A few selected cases of failure investigations (K aul et al 1996; Baldev Raj et al 1999) carried out on important components and the resultant changes made in improving the efficiency and operation of chemical/power plants are discussed in this paper.

\subsection{Failure of carbonate reboiler heat exchangers}

A few tubes of two carbonate reboiler heat exchangers of a fertiliser plant ( $B$ aldev $R$ aj et al 1999) were found to be leaking, shortly after commissioning of the heat exchangers (figure 20). As the number of leaking tubes increased continuously, operation of the heat exchangers was discontinued, and reasons for the failure of the tubes were investigated. The failed heat exchangers were made of AISI type 304 SS U-tubes and carbon steel tube sheet. The tubes were welded to the SS sheet overlaid on the carbon steel tube sheet. The tubes had been expanded to fill the tube-to-tube sheet gap. According to the design requirements, almost the full length of the tube inside the tube sheet was to be expanded. Tube-to-tube sheet welds were pneumatically tested at $0.2 \mathrm{M} \mathrm{Pa}$ before expansion of tubes into the tube sheet. B efore putting the heat exchangers into operation, passivation of the surface was carried out on the shell side for $72 \mathrm{~h}$ by circulating a solution (GV solution)

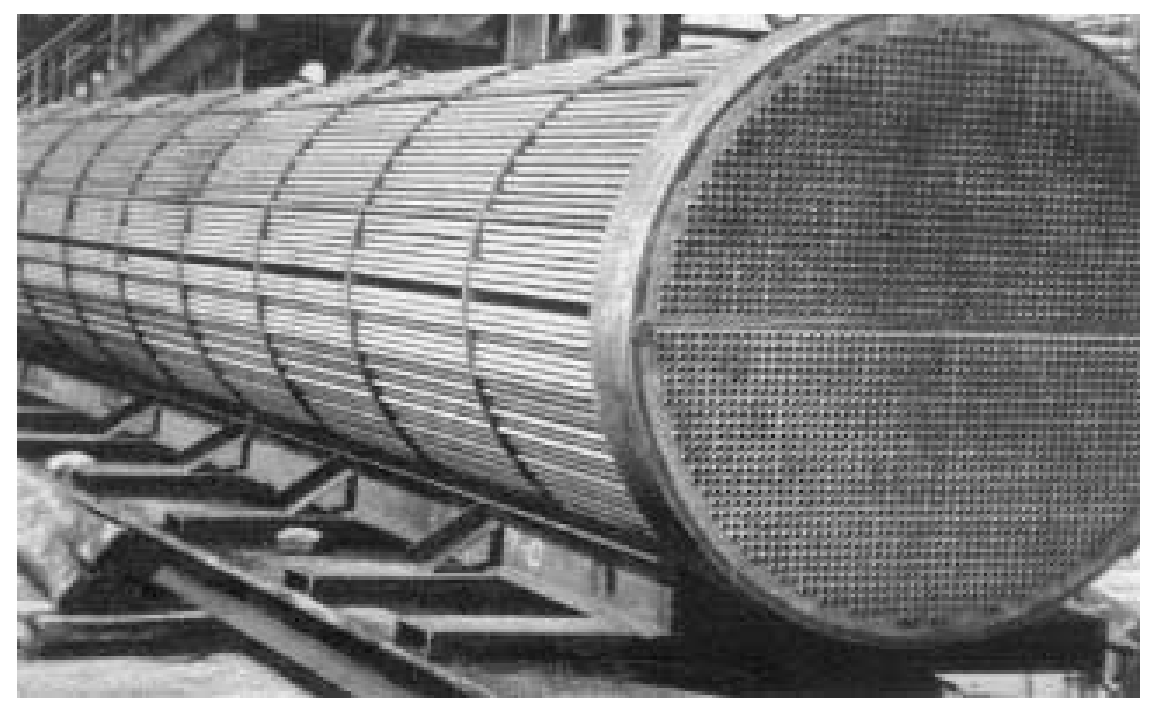

Figure 20. Photograph of a heat exchanger similar to the failed one. 


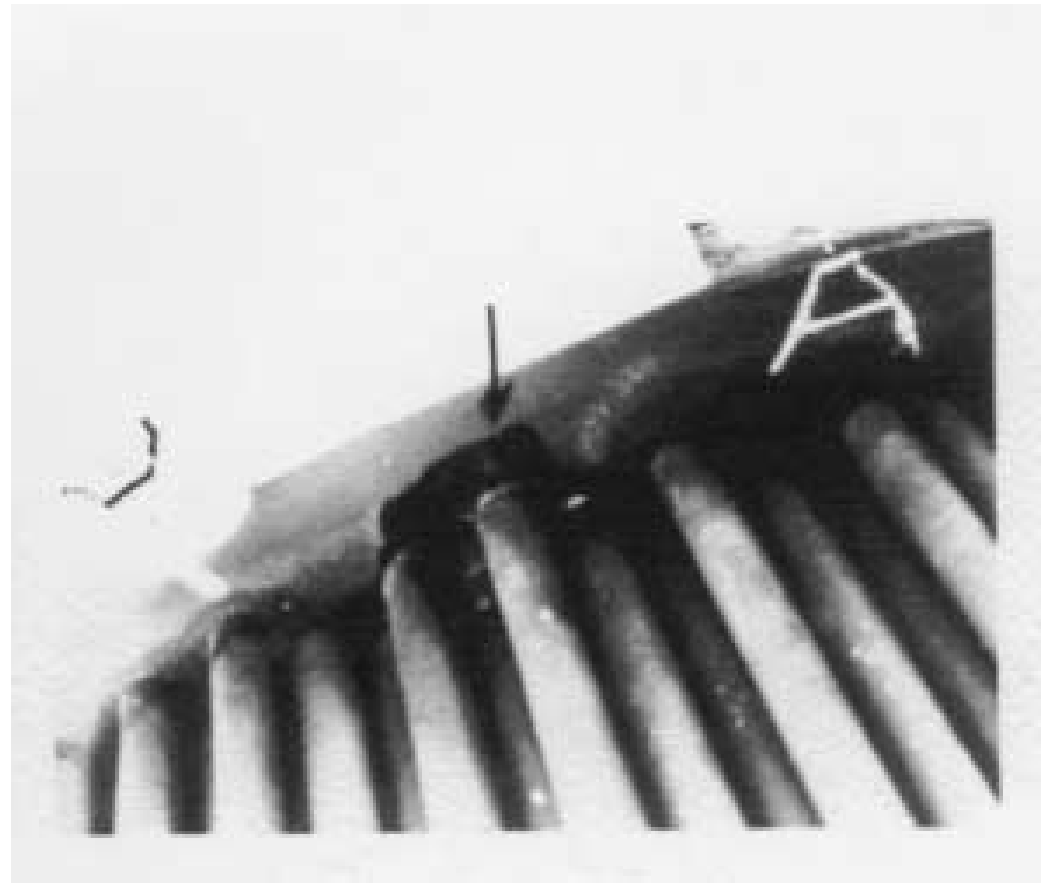

Figure 21. Failed heat exchangers with heavily corroded tube sheet.

containing $\mathrm{K}_{2} \mathrm{CO}_{3}, \mathrm{KVO}_{3}$, diethyl amine and glycine. During operation of the heat exchangers, the SS tubes carried hot process gas known as 'syngas' (a mixture of nitrogen and hydrogen) while the medium on the shell side was highly alkaline GV solution. Inlet and outlet temperatures of the 'syngas' were 436 and $399 \mathrm{~K}$ respectively. The pressures on the tube and shell side were 20 and $16 \mathrm{MPa}$ respectively.

$V$ isual examination of the failed heat exchangers revealed that the tube sheet was heavily corroded (figure 21) and the SS tubes had undergone substantial thinning from the outside surface. Inside diameteral measurements of the portion of the SS tubes indicated that the tubes had been expanded only up to a distance of about 30 to $40 \mathrm{~mm}$ from the welded end of the tube sheet while the remaining portion of about $150 \mathrm{~mm}$ length inside the tube sheet had been left unexpanded. M etallographic examination of the defective region of the tube sheet revealed extensive corrosion and uniform thinning of the SS tubes. Electrochemical investigations in GV solution under simulated plant conditions showed a tendency for pitting and crevice corrosion. Dye penetrant (DP) examination indicated nonuniform tubeto-tube sheet gaps. Precise measurements of the inside diameters of the tubes established that expansion of the full length of the tube inside the tube sheet had not occurred. This partial expansion left undesirable tube-to-tube sheet gaps, which acted as sites for crevice corrosion attack. The accumulation of ferrous ions at the crevice gap accelerated dissolution and thinning of the SS tubes and tube sheet material.

Hence to avoid similar failures, tubes inside the tube sheet should be expanded to the designed total length inside the tube sheet. Quality assurance procedures should be suitably implemented to achieve the designed features of the components. 


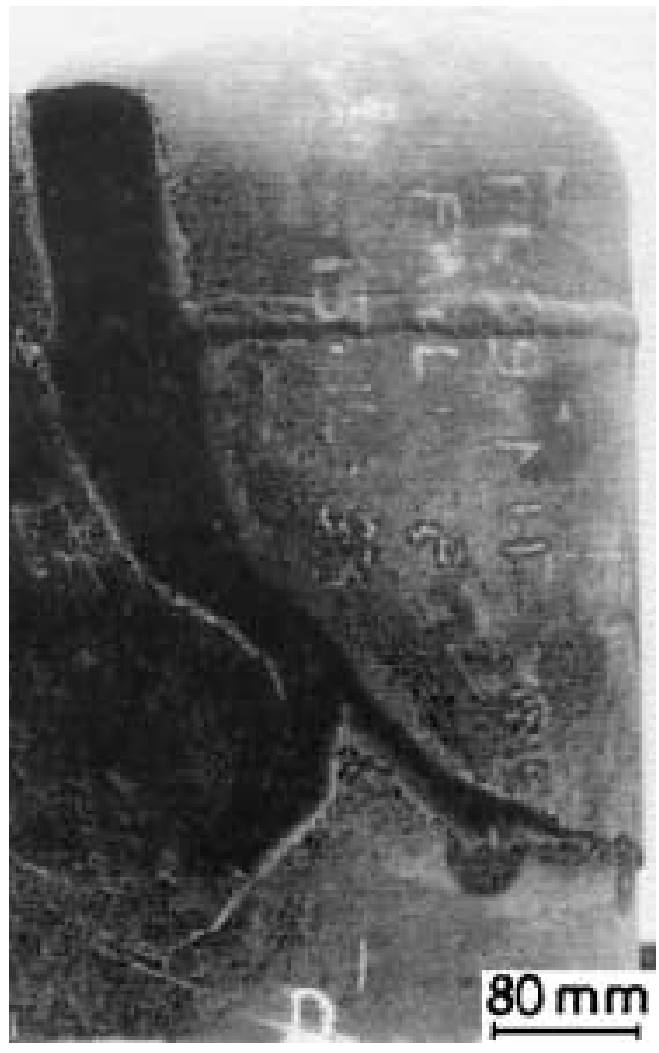

Figure 22. Photograph showing the failed ammonia refrigerant condenser.

\subsection{Failure of an ammonia refrigerant condenser tube}

Catastrophic failure of an ammonia refrigerant condenser tube (figure 22) was noticed within three hours of its operation in a chemical plant ( $K$ aul et al 1996). The concerned component was a $370 \mathrm{~mm}$ diameter pipe (with wall thickness of about $11 \mathrm{~mm}$ ) with its end welded to a hemispherical dished end (with maximum wall thickness of about $15.9 \mathrm{~mm}$ near the weld). The welded component formed the dead end of the pipe line. During its brief operating life, the component was filled with ammonia and the internal pressure dropped from $0.1 \mathrm{MPa}$ to the final pressure of $0.04 \mathrm{MPa}$ while the temperature correspondingly decreased from 270 to $241 \mathrm{~K}$. The pipe was welded to the dished end by SM AW using AWS E 6013 electrodes. The welded pipe was hydrostatically tested at a pressure of 3.2 M Pa before putting it into operation. No radiographic examination was carried out on the welds. The materials of construction of the concerned pipe and dished end were reported as API 5L Grade B and A 234 (WPB) (equivalent to A106 Gr. B) respectively. The nominal chemical composition of these materials (in wt.\%) is as follows: Pipe: $0.25 \mathrm{C} / 0.95 \mathrm{Mn} / 0.06 \mathrm{~S}$ (max.)/0.05 P (max.); Dished end: $0.30 \mathrm{C} / 0.29-1.06 \mathrm{Mn} /$ $0.058 \mathrm{~S}(\max ) / 0.048 \mathrm{P}(\max )$.

Visual examination of the failed component revealed that the pipe to dished-end weld was associated with non-uniform penetration. $X$-radiographic examination of the welded component showed lack of fusion area almost throughout the length of the weld. The weld joint was poorly designed as the tapered transition provided at the joint between sections of 
different thickness was only $3 \mathrm{~mm}$ as against the minimum specified limit of $15 \mathrm{~mm}$. Inadequate taper at the weld joint results in stress concentration in the weld region. Fractographic examination revealed brittle fracture associated with well-defined chevron marks, indicating the direction of crack propagation. The crack nucleation region, as indicated by chevron marks, showed sharp lack of penetration area. Near the crack nucleation site, fracture was found to be intergranular in nature. M etallographic examination of the specimens taken out from the weld region clearly indicated that the failure had started from lack of penetration area of the weld and that the crack was intergranular in nature. A closer look at these cracks revealed that they were emanating from the inclusion sites with blisters. These blisters form as a result of precipitation of molecular hydrogen at the matrix-particle interface. In addition, decohesion of inclusion/matrix interface was noticed. These features are characteristic signs of hydrogen embrittlement. Energy Dispersive A nalysis of $X$-rays (EDAX) of such inclusions showed the presence of $\mathrm{Fe}, \mathrm{Mn}$, $\mathrm{Ti}, \mathrm{Al}$ and $\mathrm{S}$. I mpact testing of sub-size Charpy V-notch specimens taken out from the weld region reveal ed a ductile to brittle transition temperature ( $20 \mathrm{~J}$ criterion for standard Charpy specimen) of about $265 \mathrm{~K}$ as compared to $228 \mathrm{~K}$ for base metal. Estimation of this transition temperature involved determination of transition temperature for sub-size charpy specimens using $0.25 \mathrm{~J} / \mathrm{mm}^{2}$ ligament area criterion (corresponds to $10 \mathrm{~J}$ for sub-size Charpy specimens and $20 \mathrm{~J}$ for standard Charpy specimens) and subsequent conversion to get the transition temperature for the standard Charpy specimen.

In the light of the evidence gathered during the course of the investigations, it is clear that the failure of the condenser tube started from lack of penetration area of the pipe to the dished end weld. Hydrogen absorbed at the time of welding helped in initiating the crack under the possible influence of weld residual stresses. Welding with AW S E 6013 electrode containing large amounts of cellulose in its coating is primarily responsible for formation and subsequent absorption of hydrogen in the weld puddle. During cooling of the weld metal, hydrogen solubility in matrix drops abruptly and hydrogen, in the supersaturated state, diffuses to the regions of high stress concentration (like a sharp lack of penetration area) where it can initiate a crack. This is believed to take place during storage of the component after welding. Poor weld toughness at the low temperature during start up facilitates easy crack growth and culminates in catastrophic failure as soon as the crack attains the critical length. The cause of this failure is due to improper selection of welding consumables and fabrication procedures.

It is recommended that: (i) low hydrogen electrodes (like AWS E 6016, 6018 etc.) be used for pipe to dished end weld to reduce the risk of hydrogen embrittlement as well as to improve low temperature toughness of the weld metal; (ii) proper design of the weld joint be made to avoid stress concentration when welding sections with different thicknesses; and (iii) radiographic examination of the welded component after fabrication be done to detect weld defects.

\subsection{Failure analysis of steam generator tube from a nuclear power plant}

Failure of a heat exchanger ( $\mathrm{HX}$ ) occurred in one of the nuclear power plants (figure 23) having eight boilers (Baldev Raj et al 1999). Each boiler consists of 11 heat exchanger bundles. The heat exchanger bundles are of U-tube construction consisting of 192 tubes each. The material of the heat exchanger tubes is Monel-400, having $12.0 \mathrm{~mm}$ outer diameter and $1 \mathrm{~mm}$ wall thickness. Heat exchanger tubes have $65 \mathrm{~mm}$ thick tube sheets on 


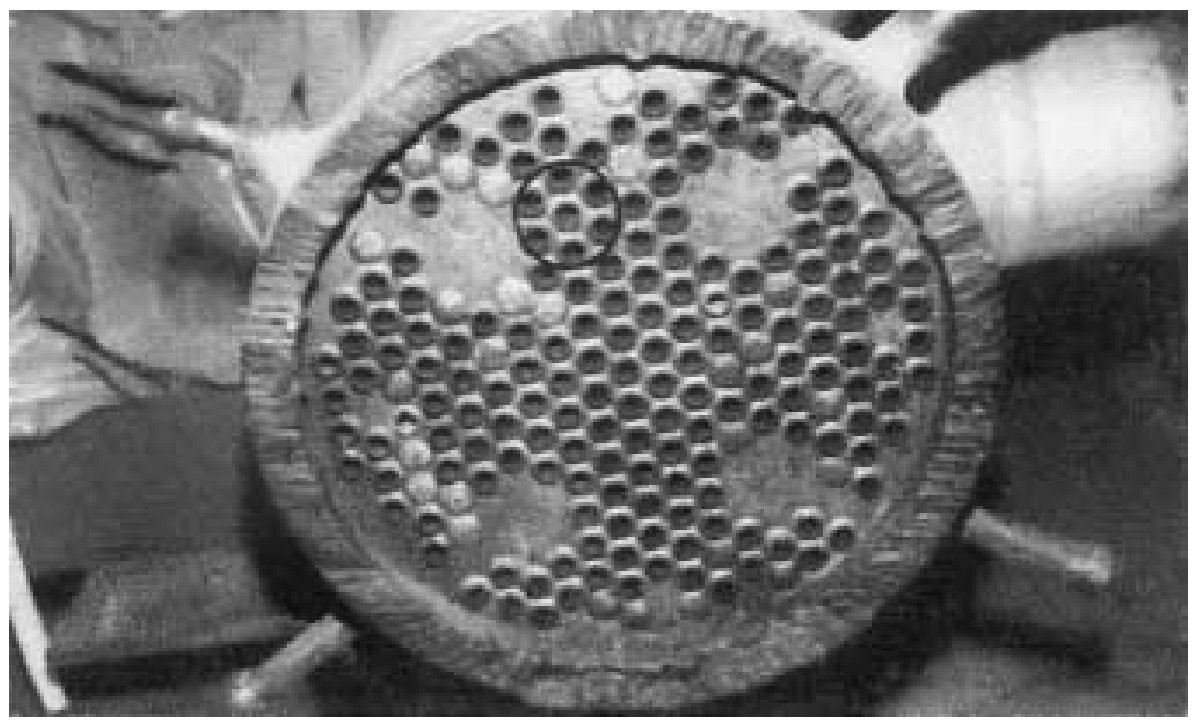

Figure 23. Photograph showing the location of the failed tube in the heat exchanger.

either leg. The tube sheet is stainless steel with M onel overlay on the outer face. The HXtubes were fully expanded in the tube sheet and welded on the outer face having the monel overlay. The tube side fluid is heavy water $\left(\mathrm{D}_{2} \mathrm{O}\right)$, with an inlet temperature of approximately $558 \mathrm{~K}$ and at a pressure of $85 \mathrm{~kg} / \mathrm{cm}^{2}$. The shell side fluid is boiler/feed water at a temperature of $533 \mathrm{~K}$ and pressure of $45 \mathrm{~kg} / \mathrm{cm}^{2}$. The failed $\mathrm{HX}$ bundle was cut out of the boiler and the leaky tube was identified by pressurisation of the shell side and by employing the soap bubble test on the tube ends. The failure location was close to the tube sheet at the $\mathrm{D}_{2} \mathrm{O}$ inlet end (boiling leg of the $\mathrm{HX}$ ).

$V$ isual inspection of the failed $\mathrm{HX}$ bundle with a window cut open from the heat exchanger shell near the $\mathrm{D}_{2} \mathrm{O}$ inlet side tube sheet showed heavy scaling of tubes, and sludge deposition on the tube sheet. To locate the defective tube and its position, a small portion of the tube sheet consisting of the failed tube along with six adjacent tubes (of about $500 \mathrm{~mm}$ length) was trepanned to carry out further studies. Visual examination of the trepanned portion of the heat exchanger revealed the absence of scaling on inside surface and adherence of sludge to the tube outer surface. A fter cleaning the trepanned portion, the presence of corrosion pits and wall thinning of all tubes covered with sludge was noticed. The defective tube showed a few pits with higher wall thickness loss. Examination of the failed tube after illuminating the tube from the inside clearly indicated a through-wall defect at the location where DP indication was seen. The inside surfaces of the tubes were examined using a fibroscope. This examination indicated only one defect location corresponding to the through-wall defect noticed earlier. All the other tube internal surfaces were seen to be clean and defect-free. However, no corrosion attack was seen on the tube sheet surfaces.

Chemical analysis indicated that the tube deposits as well as the sludge deposits on the tube sheet contained compounds of $\mathrm{Ni}, \mathrm{Cu}, \mathrm{Fe}$ and $\mathrm{Zn}$. The presence of these elements can be attributed to the material transport phenomenon in PHWR boiler feed water circuits. Radiographic examination of the defective tube showed extensive wall thinning in the pitted region. It was seen that the wall thinning extended to about $20 \mathrm{~mm}$ from the tube 
sheet location. However, no defect was noticed in the expanded region of the tube covered by the tube sheet. Radiography on three adjacent tubes, which were cut near the tube sheet, showed wall thinning and presence of corrosion pits. However, the extent of wall thinning was relatively less in these cases. No through-wall thickness defects were seen in these tubes. Stereoscopic examinations indicated the size of the defect as $0.5 \mathrm{~mm}$ width and $3 \mathrm{~mm}$ in length, at the bottom of a large shallow pit measuring approximately $10 \mathrm{~mm}$ length and $5 \mathrm{~mm}$ width on the curved surface. Conventional laboratory and in-situ metallographic techniques were carried out on the tube, close to and away from the defect region. The microstructure near a pitting defect clearly indicated extensive grain boundary attack, and extensive wall thinning due to intergranular corrosion. SEM /EDAX examination revealed that the grain boundary area near the corroded region suffered from depletion of nickel as compared to the matrix region. The corrosion products were seen to contain predominantly $\mathrm{Ni}, \mathrm{Fe}$ and $\mathrm{Cu}$ peaks, and the corrosion layer on the tube inner surface indicated peaks corresponding to sulphur.

Even though Monel-400 is used extensively as an $\mathrm{HX}$ tube material, it is known to be susceptible to intergranular attack. Pitting in the crevice regions and under deposits have been noticed in this material, on exposure to lake water. Accelerated corrosion due to oxygen generation under tailing conditions has been reported, but these are normally on the primary side of the $\mathrm{HX}$ tubes. Presence of copper/copper oxide is also seen to enhance pitting corrosion attack of Monel-400 tubes. From the morphology of the corrosion pits observed on the examined $\mathrm{HX}$-tubes and the general wall thinning seen on the tubes, it is clear that only the failed tube had undergone severe corrosion attack. Hence, sudden failure of a number of $\mathrm{HX}$ tubes at the same time was ruled out. It is also felt that failure of the tube will be through small leaks due to openings created by the formation of corrosion pits and their growth. Normally blowing down is employed to prevent accumulation of sludge deposits. Even though blowing down was adopted in the present case, its periodicity and effectiveness were not adequate. It is recommended that blowing down should be carried out more effectively.

\section{Future directions}

\subsection{Modelling and simulation}

In the next few years, more attention should be paid to the modelling and simulation of plant events in order to understand the complex phenomena occurring during damage processes. Corrosion degradation and high temperature failure of components are of major concern in the sustained operation of nuclear plants. A part from evaluating the damage processes of materials, considerable efforts are needed in the direction of predictive approaches for life estimation, evaluation and extension of the life of engineering components in service. Although a number of models are being proposed for corrosion damage assessment, the two main limitations of such models are: (i) most theoretical models tend to be simplistic leading to over conservatism, or (ii) they are limited to only a narrow range of parametric effects which limits their practical value (B aldev Raj \& Geogy George 1999). Simulation of plant events gives an idea about the eventualities that can occur due to malfunctioning of any system during operation. In a way, relevant possibilities leading to catastrophic failure of critical components can be simulated and assessed for the extent of damage. Lack of availability of successful models is due to the complex nature of 
interaction between engineering alloys, operating environments, stresses, and wide variations in characteristics of manufactured components and operating conditions. However, this complex task has to be systematically done, exploiting the knowledge base, generic architects and advanced statistical and neurofuzzy predictive methods.

\subsection{Artificial intelligence and computational learning systems}

Considering the advances taking place in the area of information technology and data processing, various data acquisition, interpretation, transfer and storage methods should be simplified and made more effective for application in plant operations. One of the emerging possibilities to effectively utilise the knowledge explosion is to explore the concepts of artificial intelligence (AI) wherever applicable. Successful implementations of Al concepts, in the form of verified and validated expert systems (ES) and knowledgebased inference mechanisms are currently being developed for various specific problems. An ES is ideally suited, (a) when problems cannot be well defined analytically, and the number of alternate solutions is large, (b) the domain of knowledge is vast, and (c) relevant knowledge needs to be identified rapidly, as it is to be used selectively. Decision Support K nowledge Package, or DESK PACK, is based on the earlier experiences of developing application-specific simple advisory 'expert' systems such as ULTREX, EDDYEX and XRADEX. The DESK PACK Software System has both symbolic and numerical modules to take care of both textual and analytical knowledge/processing. The DESKPACK framework has been used for analysing and classifying eddy current signals from artificial and natural defects, acoustic emission signals from salt mines, X-ray, MRI and SAFT (synthetic aperture focussing technique) images.

Case-based reasoning (CBR) is a selective new AI method. In CBR, previously solved problems are used to suggest solutions to new problems. CBR works on the principle that similar problems have similar solutions. In a nutshell, CBR is reasoning by remembering. When a given problem is described in the same terms as used to describe previously solved problems, the most similar already solved problem can be determined, and hence it provides an access to a possible solution to the current problem. The solution can be directly applicable after adaptation, which is based on the differences between the current problem and the problem that served to retrieve the solution, since adaptation is simpler than generation of a solution from scratch. If a new solution is found to the problem, a link between it and the problem description is created as a new case in the case base. The working cycle for CBR involves description of the problem, search for a similar previously solved problem, retrieval of the solution, adaptation of the solution, verification of the solution and storing the solved problem.

Though CBR is hardly used in NDT, it is well suited for NDT data interpretation. In some interpretation problems, the inspector uses a domain model since the underlying physical phenomena are too complex to be handled for interpretation. CBR has been applied for eddy current (EC) inspection of heat exchanger tubes. The EC signals can be interpreted from the amplitude, phase, both of these or the shape of the Lissajous patterns. M ore signal parameters are to be taken into account when the defect/damage in the tube is more complex. U sually the defect/damage is classified based on the shape of the signal and characterised using the phase and amplitude of the signal. The signals from various defects (cracks, holes, wall thinning), baffles, fins, dents, and corrosion are saved as different cases in the case base. To each case, the action to be taken for interpretation for each signal type 
is assigned. The action can be a direct classification in the case of dents etc. or application of calibration curves in the case of other defects such as wall thinning. During inspection, the data of signals are matched against those in the case base. If the match is good, then the action defined for the case is taken. However, when worse mismatches are seen, the inspector finds correct interpretation and adds the data set and the interpretation as a new case to the case base.

\subsection{Modern materials and manufacturing processes for the twenty first century}

The progress made in science and technology relating to materials is the driving force for technology innovations leading to advancements in human society. The demands for materials and processes which are cost-effective, environment-friendly and energy-efficient are on the increase and will continue to increase in the years to come. In recent years, we have witnessed the emergence of novel processes and materials totally revolutionising engineering and society. Some of these significant breakthroughs are nanophase materials, superconducting materials, composite materials, structural ceramics, smart sensors, intelligent materials, functionally graded materials, intelligent processing, on-line monitoring, containerless melting, plasma processing, laser, ion and electron-beam techniques of joining etc.

$M$ an has always used nature as a source of inspiration for engineering and technological innovations both in the design and choice of processes arguably with limited success. The advent of intelligent materials is undoubtedly an epochal development as it offers quantum improvements in several areas of technology. Synergising with artificial intelligence and neuro-computers, intelligent functions that have traditionally relied upon the use of software and electronic circuits, it is possible to embed the desired functions in intelligent materials. Biomimetics are the materials that mimic biological materials and carry out unsupervised functions with minimum energy use and degradation of the environment. Shape memory alloys are intelligent materials that have the ability to memorise their original shape and to restore the same in a predictable temperature range. For example, clamping which can automatically open and close, straight wires that can take on spiral shapes without any mechanical actions, or blocking the leak path in a tubular component is possible with shape memory alloys. A few key areas where a thrust to develop expertise and technology is relevant are: high technology ceramics for structural and other applications, smart sensors and structures, intelligent processing, development of novel materials including quasicrystals, nanostructured materials, functionally graded materials, intelligent materials, inorganic matrix composites etc., process modelling, computational materials science, surface engineering, biomimetic materials, biocoatings for corrosion resistance etc.

Production of advanced ceramics and other novel materials requires a robust process for desired product quality. This necessitates development and application of smart fieldworthy sensors, for on-line process control to obtain desired microstructure and lack of defect specification during manufacturing step, and the application of a corrective action if deviations are detected, for changing the process parameters. A variety of sensors based on physical or chemical measurements could be developed and incorporated into the process systems for 'intelligently' controlling or automating the processes. Such intelligent processing involves assembling appropriate sensors at appropriate process steps for effectively controlling the quality of the products. It is anticipated that intelligent processing of materials will become a reality through on-line measurement of the material parameters 
through NDT sensors in addition to process parameters, with suitable control through feedback of the measured parameters and application of intelligent decision-making algorithm based on statistical and neurofuzzy logic controllers. Thus, the technology to obtain tailor-made materials with consistent and predictable properties is within the reach of materials technologists. Integrated multi-sensor NDT evaluation systems for comprehensive characterisation of properties should be developed for assessment of component integrity. Such a system can be operated even by remote-control, and will form the basis of material diagnostics. Integrating this with the large materials knowledge-base, we can identify suitable therapies needed for restoring fitness for purpose of the component and even life-extension. With advancement in microelectronic technology, we can envisage the evolution of integrated corrosion and structural monitoring sensors that record all process parameters. This can then activate an intelligent defence mechanism if needed, resulting in smart structures which are corrosion-resistant. Damage-tolerant materials that can perform self-diagnosis and self-repair is another futuristic area which can usher in maintenance-free components for industries.

$\mathrm{N}$ ew materials like functionally graded materials will revolutionalise the performance of components in many aggressive environments. Smooth spatial variations in composition, and in physical and chemical properties will make this class of materials the 'darling' of the materials community in the future. Pressure vessels/pipe lines which see two different types of aggressive environments on either surface will be fabricated with a functional gradient material, whose composition and/or microstructure will be grossly different on the inside and outside surfaces and which can withstand the corresponding environments. The change in composition and/or microstructure from inside to outside can be gradual.

Production losses from wear and friction demand a new class of materials and processes, and also a new generation of thoroughly trained, knowledgeable tribologists in the next few decades. Chemical vapour deposition (CVD) and physical vapour deposition (PVD), hardcoat anodizing, composite coatings, carbon-based coatings, cryogenic tempering and wear resistant coatings by lasers are emerging in this context. Laser surface treatment can create a wear-resistant surface because it produces high hardness, suitable alloy chemistry, favourable residual stresses, fine microstructure and a smaller heat-affected zone.

Evolution in nature has led to the development of remarkable materials such as the spider's web, the abalone shell and the tortoise shell. They show outstanding combinations of strength and toughness, often superior to the materials designed by man. Inspired by biology, efforts are under way to unravel the strategy adopted by nature in terms of nanocomposites, self-assembly and hierarchical structures. Oyster shells, coral, ivory, and pearls are some of the examples of biomineralized materials engineered by living creatures in order to achieve remarkable precision and reproducibility at a molecular level. Even though the mechanisms of synthesis as well as of molecular recognition during such natural processes are not well understood, the study of biomineralization provides a unique opportunity to materials scientists to find ways of controlling and designing complex composites through interfacial chemical routes.

\section{Summary}

Various materials-related problems faced in the chemical industry necessitate looking into different aspects of materials selection, design, fabrication, inspection and quality control of engineering components in a holistic approach. A I IGCAR, totally indigenous solutions 
have been found for various materials-related problems. The solutions and the approaches used have good relevance to the chemical industry. The work and the approach related to the fabrication of an electrolytic dissolver is highlighted. Contributions of relevance in the areas of NDE, condition monitoring and failure analysis are briefly discussed. Techniques, methods, expertise and approaches can be exploited by chemical industries to search for indigenous complete solutions to challenging problems. IGCAR would be happy to be a partner to enable the achieving of better reliability and profitability in the Indian chemical industry.

The authors thank Dr. Placid Rodriguez for his inspiring guidance and support. Several scientists and engineers from the Department of A tomic Energy, who have been associated with the work referred to in this paper, are gratefully acknowledged.

\section{References}

A nanda Rao B M, Shanmugam K, K amachi M udali U, B haduri A K, Balachander K, Natarajan R 1999 Development of a titanium/304L stainless steel dissimilar metal weld joint for the nuclear fuel reprocessing plant. Proc. of the International Welding Conference IWC-99 (New Delhi: Indian Inst. Welding and Confed. Indian Ind.) pp 959-964

A nanda Rao B M, Shanmugam K, K amachi M udali U, B haduri A K, B alachander K, Natarajan R $2000 \mathrm{~A} n$ experience in fabrication, erection and piping of titanium electrolytic dissolver for FBTR fuel reprocessing. Proc. of Symposium on J oining of M aterials SOJ OM 2000 (Trichirapalli: Indian Inst. Welding and Welding Res. Inst.) pp 154-163

A SM 1975 ASM metals handbook on failure analysis and prevention 8th edn (Philadelphia, PA: Am. Soc. M etals) vol. 10

A SM 1997 ASM handbook of case histories in failure analysis (ed.) K A Esaklul (Philadelphia, PA: Am. Soc. M etals)

Baldev Raj 1994a NDE to enhance competitiveness of the Indian chemical industry. Workshop on DAE technologies, Institution of Chemical Engineers, Calcutta

B aldev Raj 1994b Evolving inspection technologies for reliable condition assessment of components and plants. INS Annual Conf. Adv. in Technologies related to Nuclear Power (NSAC-94) B habha A tomic Res. Centre, Mumbai

Baldev Raj, Geogy George 1999 Engineering approach to corrosion management. Corrosion M anagement Course, CM C-99 (Kal pakkam: Indian Inst. M etals)

Baldev Raj, Jayakumar T 1997 NDE methodologies for characterisation of defects, stresses and microstructures in pressure vessels and pipes. Int. J. Pressure Vessels Piping 73: 133-146

Baldev Raj, Kasiviswanathan K V 1997 Engineering failures: New science and improved technology. Int. Conf. Adv. in Mechanical and Industrial Engineering, University of Roorkee, pp 1-10

Baldev Raj, Kasiviswanathan K V, Jayakumar T, M uralidharan N G, Raghu N 1999 Fresh insights into the technology of heat exchangers through failure analysis and quality management. Int. J. Condition M onitor, Diagnos. Eng. Manage. 2: 19-29

Baumgartner F, Schmieder H 1978 Radiochim. Acta 25: 191

B hasin B K 1998 Unveiling the shroud inspection of reactor core shrouds at Tarapur. Nu-Power Int. 11: $14-17$

Chidambaram R 1997 Towards an energy independent India. Nu-Power Int. 11: 25-26

Gnanamoorthy J B, Balasubramanian G R 1987 Int. Atomic Energy Author., Technical Document 421: 207-241

Hayfield P C S 1973 Anodic oxidation of titanium in aqueous solutions. Titanium science and technology (eds) R Z Zaffe, H M Burte (New York: Plenum) 4: 2405-2418

IMI Report: Technical report on corrosion resistance of titanium, Imperial M etal Industries, Witton, UK 
Kalyanasundaram P, Baldev Raj, Kasiviswanathan K V, Jayakumar T, M urthy C R L 1992 Leak detection in pressure tubes of pressurised heavy water reactors by acoustic emission technique. British J. Nondestructive Testing 34:539-543

K al yanasundaram P, K asiviswanathan K V, Jayakumar T, Baldev Raj 2000 Design and development of miniature focussed differential surface eddy current probes. Indian Pat. (Pending)

K amachi M udali U, Rajan S K, Palamalai A, Gnanamoorthy J B, Rodriguez P, Balasubramanian G R 1986 Corrosion studies and materials selection for electrochemical processes applied to reprocessing of fast reactor fuels. National Symposium on Electrochemistry in Nuclear Technology (Kalpakkam: Soc. Adv. Electrochem. Sci. Technol.) paper No. 2.1

Kamachi Mudali U, Dayal R K, Gnanamoorthy J B 1990 Advanced materials of construction for spent nuclear fuel reprocessing plant equipment. Bull. Electrochem. 18: 401-405

Kamachi Mudali U, Dayal R K, G nanamoorthy J B, Rajan S K, Palamalai A 1991 Proc. Int. Symp. on Thermochemistry and Chemical Processing (Kalpakkam: Indian Inst. M etal.) pp. 293-301

Kamachi M udali U, Dayal R K, Gnanamoorthy J B $1992 \mathrm{M}$ ixed $\mathrm{RuO}_{2} / \mathrm{TiO}_{2} / \mathrm{PtO}_{2}$ coated anodes for the electrolytic dissolution of nuclear fuels. Nucl. Technol. 100: 395-402

Kamachi Mudali U, Dayal R K, Gnanamoorthy J B 1993 Corrosion studies on materials of construction for spent nuclear fuel reprocessing applications J. Nucl. Mater. $203: 73-82$

Kamachi Mudali U, Dayal R K, Gnanamoorthy J B 1995 Corrosion behaviour of weldments of advanced materials for nuclear fuel reprocessing plants. J. Mater. Eng. Performance 4: 756-760

Kamachi Mudali U, Raju V R, Dayal R K 1997 Platinised-iridium coated titanium electrodes for electrochemical applications. Proc. of the Int. Conf. on Corrosion, CORCON-97, NACE India Chapter, Bombay, pp 930-938

Kamachi Mudali U, Raju V R, Dayal R K 1998 Corrosion of advanced materials in liquid, condensate and vapour phase of nitric acid environments. Proc. Eighth National Congress on Corrosion Control (Kochi: National Corrosion Council of India) pp 7.3.1-7.3.8

Kamachi Mudali U, Kuppusami P, Raju V R, Raghunathan V S 1999a An improved process for producing mixed oxide coated titanium anodes having enhanced life in electrochemical applications and the anodes so prepared. Indian Pat. Appl. No.: 807/Bom/99, dated 17.11.99

Kamachi Mudali U, Raju V R, Dayal R K 1999b Preparation and characterisation of platinum and platinum-iridium coated titanium electrodes. J. Nucl. Mater. 277: 49-56

K amachi M udali U, Raju V R, A nanda Rao B M , Shanmugam K, Dayal R K, K hatak H S, Natarajan $R$ 1999c Microstructural changes and corrosion behaviour of dissimilar joints of titanium and 304l stainless steel developed for nitric acid service. Fifth National Convention on Corrosion NACE India Chapter, New Delhi

Kamachi Mudali $U$, et al, $2000 \mathrm{~A}$ method for developing corrosion resistant coatings for titanium equipment in nitric acid medium (to be published)

K aul R, M uralidharan N G, Kasiviswanathan K V, Baldev Raj 1996 Failures in pressure vessels and pipelines. Proc. Int. Conf. on Pipes and Pressure Vessels pp 85-93

M anjit Singh, Parulkar S K, Taliyan S S, Tanaja R, H aruray A K, Rajashekhar D V, Shajan K J, Puri RK, G ovindarajan G 1994 An indigenous system for in-service inspection of coolant channels of 235 M W PHWRs. Proc. First Natl. Symp. on Ageing Management of Nuclear Facilities, AM NF 94 (BRNS, B habha A tomic Res. Centre, M umbai) S4-31

MCNaughton K J (ed.) 1980 Materials engineering I: Selecting materials for process equipment (New York: McGraw-Hill)

Palamalai A, Rajan S K, Chinnusamy A, Sampath M, Verghese P K, Ravi T N, Raman V R, Balasubramanian G R 1991 Radiochim. Acta 55: 29

Rodriguez P, Baldev Raj 1997 Development of in-service inspection techniques for nuclear power plants in India. Int. J. Pressure Vessels Piping 73: 59-68

Rodriguez P, Lee S M 1996 Possible scenario of nuclear energy - Fast reactors. INS News 9: 11-19

Shyamsunder M T, Rajagopalan C, Baldev Raj, Dewangan S K, Rao B P C, Ray K K 2000 Pattern recognition approaches to detection and characterisation of defects by eddy current testing. Special Issue of Materials Evaluation (in press) 
Srinivasan G R, Prasad Y S R 1994 A geing management of Indian PHWRs. Proc. of First National Symposium on Ageing Management of Nuclear Facilities, AMNF-94 BRNS, Bhabha A tomic Research Centre, M umbai, IT4-1

Steele D F 1986 Corrosion control in nuclear fuel reprocessing plants. Atom March: 5-9

Thomas D E 1986 Titanium alloy corrosion resistance in nitric acid solutions. Proc. of Int. Conf. on Titanium, Dayton, Ohio, vol. 1, pp 220-240

Tender Document 1997 Tender document for the fabrication of electrolytic dissolver. Reprocessing Group, IGCA R, Kalpakkam 